\title{
Review
}

\section{A review on variation in crude glycerol composition, bio-valorization of crude and purified glycerol as carbon source for lipid production}

The corrections made in this section will be reviewed and approved by journal production editor.

Lalit R. Kumar ${ }^{\mathrm{a}}$, Sravan Kumar Yellapu ${ }^{\mathrm{a}}$, R.D. Tyagia,* Rd.tyagi@ete.inrs.ca, Xiaolei Zhang ${ }^{\mathrm{b}}$

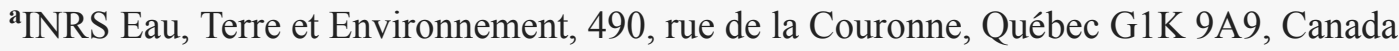

${ }^{\mathbf{b}}$ School of Civil and Environment Engineering, Harbin Institute of Technology (Shenzhen), Shenzhen, GuangDong 518055, China

*Corresponding author.

\begin{abstract}
Crude glycerol (CG) is a by-product formed during the trans-esterification reaction for biodiesel production. Although crude glycerol is considered a waste stream of the biodiesel industry, it can replace expensive carbon substrates required for lipid production by oleaginous micro-organisms. However, crude glycerol has several impurities, such as methanol, soap, triglycerides, fatty acids, salts and metals, which are created during the trans-esterification process and may affect the cellular metabolism involved in lipid synthesis. This review aims to critically present a variation in crude glycerol composition depending on trans-esterification process and impact of impurities present in the crude glycerol on the cell growth and lipid accumulation by oleaginous microbes. This study also draws comparison between purified and crude glycerol for lipid production. Several techniques for crude glycerol purification (chemical treatment, thermal treatment, membrane technology, ion-exchange chromatography and adsorption) have been presented and discussed with reference to cost and environmental effects.
\end{abstract}

Keywords: Crude glycerol; Lipid production; Inhibition; Glycerol purification; Trans-esterification

\section{Introduction}


Crude glycerol (CG) is a by-product of biodiesel industry, produced through trans-esterification. For every $10 \mathrm{~kg}$ of biodiesel produced, around one $\mathrm{kg}$ of crude glycerol is generated during the trans-esterification reaction. Crude glycerol is obtained from four different industries, i.e. soap industry, fatty acid industry, biodiesel industry and fatty ester industry. However, it can also be obtained from propylene oxide. The transesterification reaction to direct transformation of vegetable oils and animal fats into fatty acid methyl esters (FAMEs) and glycerol have been known for over a century. Trans-esterification of triglycerides such as rapeseed, palm, soybean and sunflower oils has gained significance for manufacturing of high-quality biodiesel fuel (Mootabadi et al., 2010; Zhou et al., 2008). Trans-esterification of vegetable oils to FAMEs/biodiesel can be attained through chemical catalyst and enzymes (Ayoub and Abdullah, 2012). The biodiesel production is increasing worldwide as it is produced from renewable biological sources and it does not pose environmental concerns (Zhang et al., 2016). It is the main reason for increasing quantity of crude glycerol in the market. Since crude glycerol is mainly produced as a by-product of the trans-esterification reaction, the price of crude glycerol would be determined by the demand and production of biodiesel in the future. It has been reported that 0.37 billion pounds of crude glycerol was produced in 2007 from biodiesel manufacturers (Ayoub and Abdullah, 2012). By 2020, 5.87 billion pounds of crude glycerol would be produced according to the estimated demand for biodiesel production of 8 billion gallons.

Fatty acid manufacturing industry was a strong source of crude glycerol production until the year of 1999; $47 \%$ of total crude glycerol was produced from fatty acid industry (Ayoub and Abdullah, 2012). The contribution of the fatty acid industry slowly decreased in 2009 because the biodiesel industry became the main source of crude glycerol production (64\% of total crude glycerol production). The reason behind the increased production of crude glycerol was the increased production of biodiesel in the last few years. This forced the industry and scientists to develop and/or identify innovative uses of crude glycerol to open new markets in the near future (Iyyappan et al., 2018a; Ji et al., 2019; Li et al., 2018). Application of crude glycerol in different outlets has been summarized in Table 1. Although crude glycerol has applications in several industries, its overproduction is a serious problem and alternate ways of disposal or use should be looked upon.

\section{Table 1}

The presentation of Tables and the formatting of text in the online proof do not match the final output, though the data is the same. To preview the actual presentation, view the Proof.

Worldwide crude glycerol applications to various outlets.

\begin{tabular}{|l|l|l|l|}
\hline Field of application & Application of glycerol & \multicolumn{2}{c|}{ Reference } \\
\hline Chemical Industry & $\begin{array}{l}\text { Formation of stain-resistant chemicals and use for lubrication, sizing and softening for } \\
\text { yarn and fabric }\end{array}$ & $\begin{array}{l}\text { (Anitha et } \\
\text { al., 2016) }\end{array}$ \\
\hline Commodity Chemicals & Natural organic building blocks for many organic chemicals and acids & $\begin{array}{l}\text { (Anitha et } \\
\text { al., 2016) }\end{array}$ \\
\hline & & \\
\hline
\end{tabular}




\begin{tabular}{|l|l|l|l|l|l}
\hline $\begin{array}{l}\text { Pharmaceutical and oral } \\
\text { care }\end{array}$ & Additives in drugs, heart disease drugs, health supplements, cosmetics, tanning agent & $\begin{array}{l}\text { (Mota et } \\
\text { al., 2017) }\end{array}$ \\
\hline Food & Safe sweeteners, preservation, thickening agent & $\begin{array}{l}\text { (Mota et } \\
\text { al., 2017) }\end{array}$ \\
\hline Livestock feed & Cow and other animals feed, pigs' diet, poultry feed & Liquid fuel, conversion into ethanol or hydrogen, burning as fuel pellets, combustion in \\
\hline substitution and biogas & incinerators, combustion as boiler fuel & $\begin{array}{l}\text { (Anitha et } \\
\text { al., 2016) }\end{array}$ \\
\hline Biotechnology & $\begin{array}{l}\text { Organic acid production, omega-3 fatty acids production, succinic acid production by } \\
\text { fermentation, EPA (Eicosapentaenoic acid) production by fungus }\end{array}$ & $\begin{array}{l}\text { (Anitha et } \\
\text { al., 2016) }\end{array}$ \\
\hline Miscellaneous & $\begin{array}{l}\text { Basic materials, hydraulic and fire-resistant fluid, de-icing of aircraft, thermo-chemical } \\
\text { products }\end{array}$ & $\begin{array}{l}\text { (Mota et } \\
\text { al., 2017) }\end{array}$
\end{tabular}

Crude glycerol has been continuously produced as a by-product over the past decades, which resulted in a substantial decrease in its price. Besides, the cost of purification of crude-glycerol to obtain a commercialgrade is high (Anitha et al., 2016). Price of crude glycerol (with $80 \%$ purity) decreased from $0.25 / 1 b$ US\$ to 0.05/lb US\$ (Anitha et al., 2016; Mota et al., 2017; Vivek et al., 2017). The purification process is costly for both small and medium-scale biodiesel plants. However, crude glycerol has become very competitive compared to expensive sugars due to lower price and it can be used as a carbon source for production of biomass and microbial products like intracellular lipids, citric acid, bio-plastics or bio-ethanol (Gao et al., 2016; Gong et al., 2015; Gong et al., 2016; Leite et al., 2015). In addition, converting crude glycerol to valueadded products provides an alternative route for crude glycerol disposal as well as serves to replace expensive carbon source for fermentation medium (Ganesh et al., 2015; Ji et al., 2019; Luo et al., 2016; Vivek et al., 2017; Xin et al., 2017). Although several studies have been reported on use of crude glycerol for various microbial products like citric acid, bio-ethanol, organic acids and bioplastics (Anitha et al., 2016; Dikshit and Moholkar, 2016; Iyyappan et al., 2018b; Mota et al., 2017; Rzechonek et al., 2019; Vivek et al., 2017; Wischral et al., 2016), this review is focused on the use of crude glycerol for microbial lipid production. The microbial lipids can be trans-esterified to produce biodiesel (Chen et al., 2018a; Kumar et al., 2019a,b; Yellapu et al., 2016, 2018, 2017, 2019; Zhang et al., 2019; Zhang et al., 2017). Hence, the use of crude glycerol (obtained from biodiesel industry) for microbial lipid production can be useful for maintaining the circular economy.

However, the crude glycerol solution contains impurities like methanol, water, soap, free fatty acids (FFA), salts, dissolved or suspended charcoal and chemical elements (arise from the catalyst), which can have an impact on the cell growth and intracellular lipid production (Gao et al., 2016). The concentration of contaminants in the crude glycerol varies depending on the process of trans-esterification and it is necessary to evaluate the impact of impurities present in the crude glycerol on cell growth and lipid production. This review was aimed to summarize variation in crude glycerol composition depending on trans-esterification process and the impact of several impurities present in the crude glycerol on cellular metabolism and microbial lipid synthesis by oleaginous micro-organisms. A comparative performance of crude and purified glycerol as a 
carbon source for lipid production has been presented. Different techniques for glycerol purification with respect to their cost and environmental effects have been presented and discussed.

\section{Variation in characteristics and composition of crude glycerol}

Crude glycerol has low economic value due to a low glycerol content and the presence of various contaminants. Common contaminants in the crude glycerol obtained from biodiesel industry include moisture, methanol, ash, soap, fatty acids, salts and catalyst. Crude glycerol from biodiesel industry contains about $25 \%$ carbon and elements like $\mathrm{Na}, \mathrm{Ca}, \mathrm{K}, \mathrm{Mg}, \mathrm{Na}, \mathrm{P}$, and $\mathrm{S}$ are also present (Ayoub and Abdullah, 2012). The concentration of these elements is usually in the range of 4-163 ppm, except $\mathrm{Na}$ and $\mathrm{K}$, which could exceed a concentration of $1 \%(\mathrm{w} / \mathrm{v})$. Other than chemical elements, crude glycerol also contains proteins $(0.06-0.44 \%)$, fats (1-13\%) and carbohydrates (75-83\%) (Ayoub and Abdullah, 2012).

The components in crude glycerol and their concentration may vary from industry to industry (Table 2). Crude glycerol obtained from biodiesel industry has different composition depending on the catalyst concentration, oil source used and the trans-esterification process (Dobrowolski et al., 2016). For example, the crude glycerol obtained from biodiesel industry may have high methanol content as excess methanol (molar ratio of alcohol: oil $>3: 1$ ) is used during trans-esterification reaction and unreacted methanol enters in the crude glycerol phase after phase separation. Adewale et al. (2015) used base catalyst $(\mathrm{NaOH})$ for biodiesel production by a varying molar ratio of methanol to oil between 5:1-10:1 resulting in the catalyst concentration of $1 \%-1.5 \% \mathrm{w} / \mathrm{w}$ of the oil (Adewale et al., 2015). The crude glycerol solution thus obtained during trans-esterification contained glycerol $(40 \%-50 \% \mathrm{w} / \mathrm{w})$, methanol $(20 \%-40 \% \mathrm{w} / \mathrm{w})$, water $(10 \%-15 \% \mathrm{w} / \mathrm{w})$, sodium salt of fatty acid $(0.5 \%-2 \% \mathrm{w} / \mathrm{w})$, fatty acid esters $(0.5 \%-2 \% \mathrm{w} / \mathrm{w})$ and sodium chloride $(0.5 \%-2 \% \mathrm{w} / \mathrm{w})$. On the other hand, when the acid catalyst $\left(\mathrm{H}_{2} \mathrm{SO}_{4}\right)$ was used with varying molar ratio of methanol to oil between 7:1-12:1 with the catalyst concentration of $5 \%-10 \% \mathrm{w} / \mathrm{w}$ of the oil weight, the crude glycerol solution obtained contained glycerol $(35 \%-40 \% \mathrm{w} / \mathrm{w})$, methanol $(30 \%-50 \% \mathrm{w} / \mathrm{w})$, water $(20 \%-30 \% \mathrm{w} / \mathrm{w})$ and sulphuric acid $(5 \%-10 \%$ w/w) (Veljković et al., 2015).

Table 2

i) The presentation of Tables and the formatting of text in the online proof do not match the final output, though the data is the same. To preview the actual presentation, view the Proof.

Variation in crude glycerol composition based on type of manufacturing industry.

\begin{tabular}{|l|l|l|l|}
\hline Content & Soap industryproduction & Bio-diesel industry & Tri-glyceride industryproduction \\
\hline Glycerol content \% (w/w) & 80 & $14-87$ & 42 \\
\hline Nitrogen content \% (w/w) & 0.041 & $0.014-0.078$ & 0.136 \\
\hline $\mathrm{NaCl} \%(\mathrm{w} / \mathrm{w})$ & 7.59 & $0.2-5.47$ & 1.23 \\
\hline Ash \% (w/w) & 8.76 & $0.93-6.34$ & 1.35 \\
\hline
\end{tabular}


The impurities and their concentration in crude glycerol are also dependent on the oil source used during the trans-esterification. Thompson and He (2006) characterized the crude glycerol solution obtained during transesterification of different seed oil such as canola, crambe, mustard, rapeseed, soybean, and waste cooking oil (WCO) (Thompson and He, 2006). The reaction was conducted at $50{ }^{\circ} \mathrm{C}$ and $240 \mathrm{rpm}$ for $60 \mathrm{~min}$ in the presence of sodium methylate as catalyst. The characterization of crude glycerol for different oil sources has been compared in Table 3. It was found that the carbon content in the crude glycerol obtained from all sources was around 25\% except WCO where the carbon content was $37.7 \%(\mathrm{w} / \mathrm{w})$. High carbon content was due to presence of soaps, dissolved unreacted tri-glycerides and esters in the WCO. The crude glycerol obtained from WCO had a much higher fat content (60.1\%) indicating presence of untreated tri-glycerides in the WCO. High concentration of elements $(\mathrm{Ca}, \mathrm{K}, \mathrm{Mg}, \mathrm{P}, \mathrm{S})$ in crambe glycerol was most likely due to the soil conditions where the seeds were grown (Thompson and He, 2006). The ash contained in crude glycerol is mainly coming from the catalyst and impurities of oils or fats during the trans-esterification.

\section{Table 3}

(i) The presentation of Tables and the formatting of text in the online proof do not match the final output, though the data is the same. To preview the actual presentation, view the Proof.

Crude glycerol composition based on different oil sources.

\begin{tabular}{|c|c|c|c|c|c|c|c|}
\hline Feedstock & IdaGold & PacGold & Rapeseed & Canola & Soybean & Crambe & WCO \\
\hline $\mathrm{Ca}(\mathrm{ppm})$ & 11.7 & 23 & 24 & 19.7 & 11 & 163.3 & - \\
\hline $\mathrm{K}(\mathrm{ppm})$ & - & - & - & - & - & 216.7 & - \\
\hline $\mathrm{Mg}(\mathrm{ppm})$ & 3.9 & 6.6 & 4 & 5.4 & 6.8 & 126.7 & 0.4 \\
\hline $\mathrm{P}(\mathrm{ppm})$ & 25.3 & 48 & 65 & 58.7 & 53 & 136.7 & 12 \\
\hline $\mathrm{S}(\mathrm{ppm})$ & 21 & 16 & 21 & 14 & - & 128 & 19 \\
\hline Carbon (\% wt) & 24 & 24.3 & 25.3 & 26.3 & 26 & 24 & 37.7 \\
\hline Fat $(\% \mathrm{wt})$ & 2.03 & 1.11 & 9.74 & 13.1 & 7.98 & 8.08 & 60.1 \\
\hline $\mathrm{Na}(\% \mathrm{wt})$ & 1.17 & 1.23 & 1.06 & 1.07 & 1.2 & 1.1 & 1.4 \\
\hline Ash (\% wt) & 2.8 & 1.9 & 0.7 & 0.65 & 2.73 & 0.25 & 5.5 \\
\hline
\end{tabular}

Trans-esterification of feedstock with high FFA content (over $2 \% \mathrm{w} / \mathrm{w}$ ) such as animal fat or waste cooking oils with alkaline catalysis results in soap formation. Water present during the reaction can also cause hydrolysis of triglyceride to FFA, which results in soap formation (Sanford et al., 2009). Soap may exist in the 
form of sodium oleate or potassium oleate. The crude glycerol obtained from one of the biodiesel industries had (w/v) composition: $13.24 \%$ glycerol, $10.37 \%$ water, $23.58 \%$ soap, $31.14 \%$ methanol, 3\% ash and $3.1 \%$ $\mathrm{NaOH}$ (Chen et al., 2018c). The glycerol solution obtained from other biodiesel industry contained 78\% w/w glycerol, methanol 1.28\% w/w, soap 2.4\% w/w, water 2.48\% w/w and $\mathrm{NaOH} 0.12 \% \mathrm{w} / \mathrm{w}$ (Mathiazhakan et al., 2016). Since crude glycerol may contain different impurities depending on oil source and trans-esterification process, it is important to evaluate the effect of these impurities on the cell growth and lipid synthesis by oleaginous micro-organisms.

\section{Impact of impurities present in crude glycerol on cell growth and lipid accumulation}

\subsection{Soap}

Crude glycerol (obtained from biodiesel industry) was used as the carbon substrate for lipid production using Rhodosporidium toruloides and the effect of methyl oleate and sodium oleate was investigated on lipid production (Gao et al., 2016). The crude glycerol (w/w) composition was 49\% glycerol, 18\% methanol, 30\% water, $1 \%$ sodium oleate, $1 \%$ methyl oleate and $1 \%$ sodium chloride. It was found that with increasing the sodium oleate concentration from $0 \mathrm{~g} / \mathrm{L}$ to $2 \mathrm{~g} / \mathrm{L}$ in pure glycerol, the biomass and lipid content increased by $25 \%$ and $68 \% \mathrm{w} / \mathrm{w}$, respectively. It could be due to the emulsifying nature of sodium oleate, which increased cell membrane permeability and improved the nutrient-uptake capability of $R$. toruloides. But, further increase in sodium oleate concentration (i.e. above $2 \mathrm{~g} / \mathrm{L}$ ) resulted in a decrease in biomass and lipid concentration (Gao et al., 2016). At high concentration of sodium oleate, the combined action of excess soap with cytoderm and cytomembrane can cause negative effects on cell growth and lipid accumulation. Similar types of results were obtained with increasing methyl oleate concentration. Increasing methyl oleate concentration from 0 to $20 \mathrm{~g} / \mathrm{L}$ in pure glycerol decreased biomass and lipid concentration by 6.6 and $17.7 \%$, respectively.

Dobrowolski et al. (2016) studied lipid production by yeast Yarrowia lipolytica using crude glycerol procured from different industries and the results were compared with pure glycerol. Crude glycerol obtained from soap company had following (w/w) composition; $80 \%$ glycerol, $0.041 \%$ nitrogen, $7.59 \% \mathrm{NaCl}, 8.76 \%$ fatty acids and 3.6\% water, whereas crude glycerol obtained from stearin (tri-glyceride of stearic acid) company composed of $(\mathrm{w} / \mathrm{w}): 42 \%$ glycerol, $0.136 \%$ nitrogen, $1.23 \% \mathrm{NaCl}, 1.35 \%$ ash and $55.3 \%$ water. A very long lag phase (24-30h) was observed for crude glycerol obtained from stearin production industries. However, when the crude glycerol from soap industry was used, the cell growth was higher than other crude glycerol and pure glycerol. This was due to the fact that during the saponification process in the soap industry, plant or animal fat is hydrolyzed leading to the residues of fatty esters, which were easily utilized by Y. lipolytica (as compared to glycerol alone) resulting in higher biomass and lipid production. The crude glycerol obtained from soap industry obtained $1.69 \mathrm{~g} / \mathrm{L}$ lipid concentration $(25 \% \mathrm{w} / \mathrm{w})$ with a biomass yield of $0.17 \mathrm{~g} / \mathrm{g}$ in shake

flasks. Further, the lipid concentration of $4.72 \mathrm{~g} / \mathrm{L}$ was obtained with a biomass yield of $0.21 \mathrm{~g} / \mathrm{g}$ in a bioreactor.

Chen et al. (2018c) used sludge fortified with crude glycerol as a substrate for lipid production using Trichosporon:- oleaginosus. The crude glycerol contained $31.1(\% \mathrm{w} / \mathrm{v})$ of methanol, $26.80(\% \mathrm{w} / \mathrm{v})$ of soap 
and $15.05(\% \mathrm{w} / \mathrm{v})$ of glycerol. Methanol present in the crude glycerol was evaporated during the sterilization before glycerol used as fermentation medium. The medium used for lipid production contained $30 \mathrm{~g} / \mathrm{L}$ sludge suspended solids (SS), $20.5 \mathrm{~g} / \mathrm{L}$ glycerol and $36.5 \mathrm{~g} / \mathrm{L}$ soap. Soap concentration of $36.5 \mathrm{~g} / \mathrm{L}$ proved inhibitory for cell growth. It was found that cell growth and lipid production was inhibited by the soap present in crude glycerol. Soap decreases motility of cells, impacts their orientation and transforms their morphology (Kosmela et al., 2017; Rahman et al., 2017). To prevent soap inhibition on T. oleaginosus, pH of the media was optimized by Chen et al. (2018c). It was found that at neutral $\mathrm{pH}$ (6.5-7) significant inhibition was observed in the medium due to presence of soap. By conversion of soap to free fatty acid (FFA) at pH 5, the soap inhibition was prevented. It was found that $98.71 \%$ of soap was converted to FFA at $\mathrm{pH} 5$, while soap conversion was $87.01 \%$ at $\mathrm{pH} 6$ and $0 \%$ at $\mathrm{pH}$ 7. Based on $\mathrm{pH}$ optimization, a $\mathrm{pH}$ based fed-batch fermentation was employed to produce lipid using $T$. oleaginosus where fermentation $\mathrm{pH}$ was maintained at 5 by using crude glycerol as pH adjusting agent (Chen et al., 2018c). Crude glycerol (after sterilization, $\mathrm{pH}$ 10.98) was used for $\mathrm{pH}$ control ( $\mathrm{pH} 5$ ) and feeding. Once the $\mathrm{pH}$ decreased due to production of organic acids, the crude glycerol ( $\mathrm{pH} 10.98)$ was pumped into the fermenter through the control system. During the fed-batch fermentation, soap existed in the form of FFA because the fermentation $\mathrm{pH}$ was at 5. No inhibition of FFA (oleic acid) was observed on $T$. oleaginosus and both FFA and glycerol were simultaneously used by microbe. From the $\mathrm{pH}$ based fed-batch fermentation, a remarkably high biomass $(65.63 \mathrm{~g} / \mathrm{L})$ and lipid $(35.79 \mathrm{~g} / \mathrm{L})$ concentration were achieved (Chen et al., 2018c).

\subsection{Effect of glycerides and fatty acids}

After trans-esterification reaction, biodiesel is separated from crude glycerol through phase separation or centrifugation. However, there are still some glycerides and fatty acid methyl esters (FAMEs/biodiesel) molecules in the aqueous glycerol phase. Since oleic acid and monoglycerides are also present in the crude glycerol, the effect of methyl oleate and glyceryl monooleate on cell growth and lipid accumulation by $R$. toruloides were investigated ( $\mathrm{Xu}$ et al., 2012). Adding methyl oleate $(0.5-2 \mathrm{~g} / \mathrm{L})$ in pure glycerol medium increased the biomass concentration by $9-12 \%$ and lipid concentration by $7-22 \%$. Fortification of glyceryl monooleate $(0.5-2 \mathrm{~g} / \mathrm{L})$ in pure glycerol, increased the biomass concentration by $8-13 \%$ and lipid concentration by $10-16 \%$, respectively. Yeast cells can use oils like glycerides by first hydrolyzing them to free fatty acids and then using them as carbon source (Beopoulos et al., 2009). Glycerides and FAMEs have hydrophilic and hydrophobic groups acting as a "weak" surfactant (compared with soap), and have interactions with cell membranes altering its permeability (Ta et al., 2010).

In one of the studies, crude glycerol with following (w/v) composition: $31.14 \%$ methanol, $26.80 \%$ soap and $15.05 \%$ glycerol was used for lipid production by T. oleaginosus (Chen et al., 2017). The batch fermentation was conducted using sterilized crude glycerol at $\mathrm{pH} 5$ where soap was converted to FFA. The fermentation was started with $23 \mathrm{~g} / \mathrm{L}$ FFA and $15 \mathrm{~g} / \mathrm{L}$ glycerol while methanol was evaporated during the sterilization. It was observed that both FFA and glycerol were readily used by microbe during fermentation. High consumption rates of $0.6 \mathrm{~g} / \mathrm{L} / \mathrm{h}$ FFA and $0.25 \mathrm{~g} / \mathrm{L} / \mathrm{h}$ glycerol were attained, which led to high biomass $(0.44 \mathrm{~g} / \mathrm{L} / \mathrm{h})$ and lipid productivity $(0.22 \mathrm{~g} / \mathrm{L} / \mathrm{h})$ during the fermentation indicating no inhibition of $T$. oleaginosus from FFA.

\subsection{Methanol}


The effect of impurities is specific to microbial strain and its metabolism. Effect of methanol concentration was investigated on lipid production using T. oleaginosus (Chen et al., 2018d). The crude glycerol obtained from biodiesel industry had composed (w/v): 13.24\% glycerol, 10.37\% water, $23.58 \%$ soap, 31.14\% methanol, $3 \%$ ash and 3.1\% NaOH. Non-sterilized crude glycerol adjusted to different methanol concentrations of $1.4 \%$ $(\mathrm{w} / \mathrm{v}), 2.2 \%(\mathrm{w} / \mathrm{v}), 3.3 \%(\mathrm{w} / \mathrm{v})$ and $4.4 \%(\mathrm{w} / \mathrm{v})$ was used as the lipid production medium. Maximum biomass $(12.64 \mathrm{~g} / \mathrm{L})$ and lipid concentration $(3.29 \mathrm{~g} / \mathrm{L})$ were obtained at $42 \mathrm{~h}$ with $1.4 \%(\mathrm{w} / \mathrm{v})$ methanol in batch fermentation, respectively. Increase in methanol concentration decreased biomass and lipid concentration due to the toxic effects of methanol on both the cell growth and the lipid accumulation. Although contaminants (colonies besides T. oleaginosus) were also growing along with T. oleaginosus, the presence of contaminants was not responsible for low lipid production. It was found that methanol was barely used by microbes, but did not impact growth and lipid accumulation at $1.4 \%(\mathrm{w} / \mathrm{v})$. At $42 \mathrm{~h}$, all FFA and glycerol were used as carbon source and after $42 \mathrm{~h}$, stored lipid was used by microbes as a carbon source to support cell growth. However, when fermentation was conducted in a fed-batch mode with non-sterilized crude glycerol (with $1.4 \%$ w/v methanol), high biomass $(43.22 \mathrm{~g} / \mathrm{L})$ and lipid concentration $(20.78 \mathrm{~g} / \mathrm{L})$ were obtained at $60 \mathrm{~h}$. Although with fed-batch fermentation 48\% lipid content was observed, methanol was still left unutilized while glycerol and FFA were consumed by microbes.

Two different crude glycerol solutions were used for lipid production by $R$. toruloides (Xu et al., 2012). Crude glycerol A obtained from alkaline-catalyzed process had (w/w) composition: $85.19 \%$ glycerol, 6.52\% ash content and $0.09 \%$ biodiesel. The crude glycerol B obtained from enzyme-catalyzed process had (w/w) composition: $32.97 \%$ glycerol, $14.89 \%$ methanol, $1.81 \%$ biodiesel and $0.11 \%$ ash. The biomass obtained by using glucose, refined glycerol, crude glycerol A and B were $14.4 \mathrm{~g} / \mathrm{L}, 12.8 \mathrm{~g} / \mathrm{L}, 19.2 \mathrm{~g} / \mathrm{L}$ and $20.1 \mathrm{~g} / \mathrm{L}$, respectively; while lipid obtained were $7.2 \mathrm{~g} / \mathrm{L}$ (glucose), 5.6 g/L (refined glycerol), 9.2 g/L (A) and 8.6 g/L (B), respectively at $160 \mathrm{~h}$ in shake-flasks. Compared to glucose and refined glucose higher biomass and lipid concentration were obtained in crude glycerol. This was due to the fact that crude glycerol possesses impurities such as salts and soap, which exerted a positive impact on the yeast growth and lipid accumulation. Considering the individual effect, soap, $\mathrm{NaCl}$ and triglycerides had a positive impact on biomass and lipid concentration, while methanol had an inhibitory impact on biomass and cell growth. The lipid concentration and lipid yield were decreased by $5-6 \%$ on adding $4 \mathrm{~g} / \mathrm{L}$ methanol. The lipid concentration further reduced to $24 \%$ on increasing methanol concentration in the medium to $16 \mathrm{~g} / \mathrm{L}$.

The impact of methanol present in the crude glycerol on Ustilago maydis was investigated, which is a producer of glycolipid biosurfactant (Liu et al., 2011). The crude glycerol used was obtained from a biofuel industry (composition not reported). Different concentrations of methanol $(0 \%, 2 \%, 5 \%$ and $10 \%$, v/v) were fortified with pure substrates like glucose and glycerol. The addition of $2 \%$ methanol inhibited cell growth along with glycolipid production irrespective of the carbon source. Also, a significant drop in carbon source utilization was observed. At $5 \% \mathrm{v} / \mathrm{v}$, cell growth and glycolipid production were stopped. These results demonstrate that the methanol concentration $>2 \% \mathrm{v} / \mathrm{v}$ was inhibitory to cell growth and production of glycolipids. The presence of methanol in the growth medium can induce osmotic phenomena at microbial cells and affects the membrane fluidity, transport mechanisms and the activity of enzymes involved in the membrane function. 
In the other study, the effect of methanol in $50 \mathrm{~g} / \mathrm{L}$ pure glycerol was investigated on lipid production by $R$. toruloides (Yang et al., 2014). It was found that adding $4 \mathrm{~g} / \mathrm{L}$ methanol in pure glycerol decreased biomass concentration from $17.7 \mathrm{~g} / \mathrm{L}$ to $16.7 \mathrm{~g} / \mathrm{L}$ and lipid concentration from $6.2 \mathrm{~g} / \mathrm{L}$ to $5.7 \mathrm{~g} / \mathrm{L}$. Inhibition by methanol presence might be due to the alteration of membrane fluidity by methanol.

To investigate the effect of methanol on biomass growth and lipid production, different concentrations of crude glycerol $(25 \mathrm{~g} / \mathrm{L}$ to $35 \mathrm{~g} / \mathrm{L})$ were employed in batch fermentation for which methanol concentration in the medium was $4 \mathrm{~g} / \mathrm{L}=-8.5 \mathrm{~g} / \mathrm{L}$ (Liang et al., 2010). The micro-organism used for lipid production was marine microalgae, S. limacinum while (w/w) composition of crude glycerol obtained from biodiesel industry was $48.7 \%$ glycerol, $9.7 \%$ methanol and $40 \%$ water. It was found that methanol was not consumed by $S$. limacinum cells throughout fermentation in either case. However, the methanol concentration below $10 \mathrm{~g} / \mathrm{L}$ did not prove inhibitory for cell growth and lipid production.

\subsection{Salts}

In base-catalyzed trans-esterification reaction, sodium hydroxide, potassium methoxide, or potassium hydroxide are normally used as the catalyst. After trans-esterification, sodium/ potassium remains in glycerol phase in the form of salts or ions.

To study the impact of $\mathrm{NaCl}$ on biomass and lipid accumulation by $R$. toruloides, different concentration of $\mathrm{NaCl}$ was added to pure glycerol medium (Xu et al., 2012). It was found that the addition of $4-16 \mathrm{~g} / \mathrm{L} \mathrm{NaCl}$ in pure glycerol increased the biomass concentration, lipid concentration and lipid yield by $12-40 \%, 20-48 \%$ and 9-20\%, respectively. The reason could be that $\mathrm{NaCl}$ alters the physiological state in favor of lipid synthesis ( $\mathrm{Xu}$ et al., 2012). The presence of increased salt concentration leads to an increased production of carbohydrates and lipids in the cell as osmo-protectants (Xu et al., 2012).

In one of the studies, the effect of $\mathrm{NaCl}$ was investigated on lipid production by $R$. toruloides (Gao et al., 2016 ). It was found that the addition of $16 \mathrm{~g} / \mathrm{L} \mathrm{NaCl}$ to pure glycerol increased biomass and lipid concentration by $35 \%$ and $64 \%$, respectively (Gao et al., 2016). Increasing $\mathrm{NaCl}$ concentration provided oleaginous microbe with osmoregulation and a good physiological state for growth and reproduction.

The effect of salt stress on lipid and triacyl glyceride (TAG) accumulation in Dunaliella cells has been investigated (Takagi and Yoshida, 2006). An increasing $\mathrm{NaCl}$ concentration to $1.0 \mathrm{M}$ resulted in a higher intracellular lipid content (67\%) in comparison with $0.5 \mathrm{M} \mathrm{NaCl}(60 \%$ lipid content). The further addition of 0.5 or $1.0 \mathrm{M} \mathrm{NaCl}$ at mid-log phase during the cultivation with initial $\mathrm{NaCl}$ concentration of $1.0 \mathrm{M}(23 \mathrm{~g} / \mathrm{L})$ further increased the lipid content to $70 \%$. However, inhibition of cell growth was observed when $\mathrm{NaCl}$ concentration was higher than $1.5 \mathrm{M}$. This study clearly indicates that certain concentrations of sodium in the medium is essential for cell growth and lipid production. However, high sodium concentration in the medium presents a dual toxicity: ionic stress and hyperosmotic stress. One factor contributing to ionic toxicity is the capacity of sodium to displace potassium or in some cases magnesium on the active sites of some enzymes, which leads to inhibition of cellular enzymes and activities (Yenush, 2016). To avoid sodium toxicity, cells actively maintain a high $\mathrm{K}^{+} / \mathrm{Na}^{+}$ratio by $\mathrm{P}$ type $\mathrm{Na}^{+} \mathrm{K}^{+}$ATPases, which drive sodium out of the cell in exchange for potassium. 
To study the impact of salt concentration on lipid production by $R$. toruloides, different concentrations of $\mathrm{K}_{2} \mathrm{HPO}_{4}(0-2 \mathrm{~g} / \mathrm{L})$ was added to $50 \mathrm{~g} / \mathrm{L}$ pure glycerol (Yang et al., 2014). It was found that the addition of $0.5 \mathrm{~g} / \mathrm{L} \mathrm{K}_{2} \mathrm{HPO}_{4}$ in pure glycerol increased the biomass concentration from $17.7 \mathrm{~g} / \mathrm{L}$ to $20.1 \mathrm{~g} / \mathrm{L}$ and lipid concentration from $6.2 \mathrm{~g} / \mathrm{L}$ to $8.6 \mathrm{~g} / \mathrm{L}$, respectively. But, further increase in $\mathrm{K}_{2} \mathrm{HPO}_{4}$ concentration in the medium slightly inhibited the lipid production. The lipid concentration obtained after adding $1 \mathrm{~g} / \mathrm{L} \mathrm{K}_{2} \mathrm{HPO}_{4}$ and $2 \mathrm{~g} / \mathrm{L} \mathrm{K}_{2} \mathrm{HPO}_{4}$ was $6.6 \mathrm{~g} / \mathrm{L}$ and $5.6 \mathrm{~g} / \mathrm{L}$, respectively (Yang et al., 2014). This study clearly indicates that certain concentrations of potassium in the media is certainly important for cellular activities because potassium is necessary for maintaining cell volume, enzyme activity, compensation of negative charges of macromolecules to electroneutrality, protein synthesis, maintenance of intracellular $\mathrm{pH}$ and membrane potential (Yenush, 2016). However, high extracellular potassium concentration is detrimental for cell growth and lipid production. High extracellular potassium concentration has reported to lead to hyperosmotic stress conditions leading to hampering of the cellular activities required for the cell growth (Yenush, 2016). Thus, high potassium concentration in the crude glycerol might affect the cell growth and intracellular lipid production. However, the exact concentration of potassium may depend on the strain used. Here, $0.36 \mathrm{~g} / \mathrm{L}$ potassium proved inhibitory for biomass and lipid concentration in $R$. toruloides.

Different concentrations of $\mathrm{K}_{2} \mathrm{SO}_{4}(0-8 \mathrm{~g} / \mathrm{L})$ was added to $50 \mathrm{~g} / \mathrm{L}$ pure glycerol for lipid production using $R$. toruloides (Yang et al., 2014). Increasing the $\mathrm{K}_{2} \mathrm{SO}_{4}$ concentration from $0 \mathrm{~g} / \mathrm{L}$ to $8 \mathrm{~g} / \mathrm{L}$ increased both biomass concentration from $17.7 \mathrm{~g} / \mathrm{L}$ to $20.9 \mathrm{~g} / \mathrm{L}$ and lipid concentration from $6.2 \mathrm{~g} / \mathrm{L}$ to $7.6 \mathrm{~g} / \mathrm{L}$ respectively. The presence of $\mathrm{K}_{2} \mathrm{SO}_{4}$ provided sulphur element, which is essential for the provision of acyl-S-CoA and Scontaining amino acids.

\subsection{Metals and non-metals}

Effect of metal ions on lipid production by fungi Cunninghamella bainieri has been investigated (Shuib et al., 2014). The fungus produced up to $8.42 \mathrm{~g} / \mathrm{L}$ biomass with $32 \%$ lipid content during nitrogen limitation. However, in spite of carbon source abundance in the medium, the lipid accumulation stopped at $48 \mathrm{~h}$ of cultivation. This was attributed to the diminishing activity of enzymes required for lipid production such as malic enzyme (ME), fatty acid synthase (FAS), and ATP citrate lyase (ACL). However, an increment in biomass from $8.42 \mathrm{~g} / \mathrm{L}$ to $14.77 \mathrm{~g} / \mathrm{L}$ and lipid content of $32 \%$ to $50 \%$ (g/g biomass) was observed when simultaneous feeding of $1 \mathrm{~g} / \mathrm{L}$ ammonium and metal ions $\left(1.5 \mathrm{~g} / \mathrm{L} \mathrm{Mg}^{2+}, 0.0001 \mathrm{~g} / \mathrm{L} \mathrm{Mn}{ }^{2+}, 0.1 \mathrm{~g} / \mathrm{L} \mathrm{Fe}{ }^{3+}\right.$, $0.0001 \mathrm{~g} / \mathrm{L} \mathrm{Cu}^{2+}, 0.0001 \mathrm{~g} / \mathrm{L} \mathrm{Co}^{2+}, 0.1 \mathrm{~g} / \mathrm{L} \mathrm{Ca}^{2+}$, and $0.0001 \mathrm{~g} / \mathrm{L} \mathrm{Zn}^{2+}$ ) was applied. This showed that lipid accumulation stopped because of exhaustion of the metal ions in the medium. Iron is vital for cell metabolism as it impacts the transfer of electrons, DNA synthesis and nitrogen fixation (Concas et al., 2014). $\mathrm{Fe}^{3+}$ may serve as a cofactor for the key lipogenic enzymes such as ME and ACL. Calcium is vital for the maintenance and stability of the membrane and formation of cell membrane and cytoskeleton (Huang et al., 2014).

Effects of $\mathrm{Fe}^{3+}, \mathrm{Mg}^{2+}$ and $\mathrm{Ca}^{2+}$ on the biomass and lipid accumulation using heterotrophic microalgae Scenedesmus sp. were studied (Ren et al., 2014). The biomass and lipid production displayed an increasing trend with the increase of the metal ion concentration. In cultures with $1.2 \times 10^{-3} \mathrm{~g} / \mathrm{L} \mathrm{Fe}^{3+}, 7.3 \times 10^{-3} \mathrm{~g} / \mathrm{L}$ $\mathrm{Mg}^{2+}$ and $9.8 \times 10^{-4} \mathrm{~g} / \mathrm{L} \mathrm{Ca}^{2+}$ in the medium, the maximum biomass, total lipid content and lipid productivity reached $3.49 \mathrm{~g} / \mathrm{L}, 47.4 \%$ and $275.7 \mathrm{mg} / \mathrm{L} / \mathrm{d}$, respectively. Compared with the control (without addition of trace 
elements), the total lipid content and lipid productivity increased by $28.2 \%$ and $29.7 \%$, respectively. An increase in $\mathrm{Mg}^{2+}$ promoted the ACCase (Acetyl carboxylase) in vivo activity and led to increase in the neutral lipid content in microalgal cells (Huang et al., 2014). Calcium plays a critical role in the signal transduction of environmental stimuli. A recent study found that an increase in the cytosolic $\mathrm{Ca}^{2+}$ level via the $\mathrm{Ca}^{2+}$ channels transmitted $\mathrm{Ca}^{2+}$ signals to regulate neutral lipid synthesis in Chlorella sp. E2(Chen et al., 2014). Further, the EDTA addition $\left(1.0^{*} 10^{-3} \mathrm{~g} / \mathrm{L}\right)$ enhanced the metal ions (iron and calcium) solubility, which promote the lipid accumulation by increasing nutrient availability to cells. But, beyond the above-mentioned concentration, metals had an inhibitory effect on cell growth and lipid production. Appropriate concentrations of metal ions and EDTA in the culture medium were favorable for lipid accumulation in Scenedesmus sp.

The effects of the concentration of the medium components on the total cell number and lipid content for the yeast Lipomyces starkeyi have been examined (Naganuma et al., 1985). The addition of $1.34 \mathrm{~g} / \mathrm{L} \mathrm{NH}_{4}{ }^{+}$, $0.32 \mathrm{~g} / \mathrm{L} \mathrm{K}^{+}, 0.05 \mathrm{~g} / \mathrm{L} \mathrm{Mg}^{2+}, 0.075 \mathrm{~g} / \mathrm{L} \mathrm{PO}_{4}{ }^{3-}, 0.12 \mathrm{~g} / \mathrm{L} \mathrm{SO}_{4}{ }^{2-}, 0.5 \mathrm{~g} / \mathrm{L} \mathrm{Fe}^{3+}$, or $0.022 \mathrm{~g} / \mathrm{L} \mathrm{Mn}^{2+}$ increased the total cell number. Beyond these concentrations, inhibitory effect on cell number and lipid content was observed. The deficiency of $\mathrm{Zn}^{2+}$ increased the lipid content by 2.4 to 2.8 times when compared with that of the control. $\mathrm{Na}^{+}, \mathrm{Cl}^{-}, \mathrm{Cu}^{2+}, \mathrm{BO}_{3}{ }^{2-}, \mathrm{I}^{-}, \mathrm{MoO}_{4}{ }^{2-}$, and biotin had almost no effect on the total cell number, lipid content, and lipid yield of L. starkeyi (Naganuma et al., 1985).

The influence of $\mathrm{Ca}^{2+}, \mathrm{Mg}^{2+}, \mathrm{Mn}^{2+}$, and $\mathrm{Fe}^{2+}$ ions on lipid production by Mortierella sp. S-17 has been investigated (Šajbidor et al., 1992). A beneficial effect of $\mathrm{Mn}^{2+}$ in the concentration range of 2-500 $\mathrm{mg} / \mathrm{L} \mathrm{on}$ lipid production was observed when compared to control. The other elements $\left(\mathrm{Ca}^{2+}, \mathrm{Mg}^{2+}\right.$ and $\left.\mathrm{Fe}^{2+}\right)$ around $50 \mathrm{mg} / \mathrm{L}$ repressed lipid accumulation. They enhanced lipid production when imparted in concentration range of $2-5 \mathrm{mg} / \mathrm{L}$.

Effect of phosphorus on lipid accumulation has been reported on Chlorella sp (Liang et al., 2013). The lipid content of Chlorella increased with increasing phosphorus concentrations from 16 to $32 \mu \mathrm{M}$. However, it was negatively impacted when phosphorus concentration was higher than $32 \mu \mathrm{M}$. The lipid synthesis is catalyzed by acetyl-CoA carboxylase (ACCase), by which acetyl-CoA is converted to malonyl-CoA followed by fatty acid after continuous cycles. Meanwhile, lipid biosynthesis is attributed to both fatty acid and glycerol-3phosphate (Lv et al., 2010). The ACCase is generally considered to catalyze the first reaction of the fatty acid biosynthetic pathway and conversion of acetyl-CoA into malonyl-CoA (Kuttiraja et al., 2018). During low phosphorus concentration in the medium, the rates of cell division and expansion were slowed (Kavanová et al., 2006). Hence, excess of a carbon source is continuously absorbed by cells, which can enter the Krebs cycle to stimulate the TAG biosynthesis (Ratledge and Wynn, 2002). Under low-phosphorus concentration, lipid content is increased, and the activity of ACCase might be enhanced (Liang et al., 2013). Therefore, it can be suggested that low-phosphorus cultivation condition could increase not only lipid content, but also lipid productivity.

From the above studies, it can be concluded that contaminants in the crude glycerol, i.e. methanol, soap, triglycerides, fatty acids, FAME, salts, metals can have either positive effect or negative effect on cell growth depending the on the strain type, its cellular metabolism and the concentration of the impurity. Hence, is 
important to know the performance of purified glycerol as a carbon source for cell growth and lipid production.

\subsection{Comparison of purified and crude glycerol as carbon source}

Chen et al. (2018b) conducted lipid production using pure glycerol, crude glycerol and purified glycerol employing T. oleaginosus. The purified glycerol was obtained by removing soap from crude glycerol with the addition of $\mathrm{H}_{3} \mathrm{PO}_{4}\left(2 \mathrm{~mL} \mathrm{H}_{3} \mathrm{PO}_{4} / 40 \mathrm{~mL}\right.$ crude glycerol). The addition of $\mathrm{H}_{3} \mathrm{PO}_{4}$ converted soap to FFA and was allowed for phase separation for $72 \mathrm{~h}$. Lipid concentration obtained in $72 \mathrm{~h}$ fermentation from pure glycerol, crude glycerol and purified glycerol was $5.35 \mathrm{~g} / \mathrm{L}, 2.92 \mathrm{~g} / \mathrm{L}$ and $4.57 \mathrm{~g} / \mathrm{L}$, respectively. The results showed that purified glycerol provided similar performance as pure glycerol in lipid accumulation. Glycerol concentration in the purified glycerol medium was further optimized for lipid production by $T$. oleaginosus. Biomass eoneentration and lipid concentration obtained with $50 \mathrm{~g} / \mathrm{L}$ purified glycerol were $10.75 \mathrm{~g} / \mathrm{L}$ and $5.24 \mathrm{~g} / \mathrm{L}(47 \% \mathrm{w} / \mathrm{w}$ lipid content) with a lipid yield of $0.19 \mathrm{~g} / \mathrm{g}$ glycerol.

Pott et al. (2014) used crude glycerol obtained from the biodiesel industry (contaminated with saponified fatty acids, SFAs) for cell growth by Rhodopseudomonas palustris, which is a hydrogen producer (Pott et al., 2014 ). The study examined the inhibition of $R$. palustris by SFAs and concluded that an SFA concentration of $0.2 \mathrm{mM}$ proved inhibitory for cell growth. Methods for purifying crude glycerol examined were given the following treatments; (i) treatment with activated carbon, $\mathrm{AC}$ (ii) $\mathrm{pH}$ adjustment to $4-5$ by $\mathrm{HCl}$ (iii) solvent extraction (using hexane or petroleum ether) and (iv) precipitation of the fatty acids with calcium chloride and calcium nitrate. It was found that the specific growth rate using purified glycerol obtained from $\mathrm{pH}$ adjustment was similar to pure glycerol $\left(0.065 \mathrm{~h}^{-1}\right)$. However, specific growth rate using purified glycerol obtained by treatment with activated carbon $\left(0.06 \mathrm{~h}^{-1}\right)$, and calcium precipitation $\left(0.05 \mathrm{~h}^{-1}\right)$ were relatively lower. A solvent extraction technique for removal of saponified fatty acids was effective when used in conjunction with $\mathrm{pH}$ adjustment. This is because salts of fatty acids are poorly soluble in non-polar solvents unless they become protonated by the addition of an acid. Although the study was conducted for hydrogen producing microbes, but the above-mentioned crude glycerol purification techniques can be applied for lipid production.

Use of marine microalgae Schizochytrium limacinum SR21 for lipid production using crude-glycerol as substrate has been reported (Liang et al., 2010). The crude glycerol used in the study was derived from two biodiesel manufacturers - i) Source 1 with following (w/w) composition: 48.7\% glycerol, 3\% soap, 22.7\% methanol and 25.6\% water and ii) Source 2 with following (w/w) composition: $42.3 \%$ glycerol, 9.6\% water and $48.7 \%$ other impurities. The Source 1 glycerol was treated by $\mathrm{pH}$ adjustment to 1 and then centrifuged to remove a dark red colored layer of FFAs (soap removal). Treated glycerol source 1 resulted in twice the lipid productivity and substrate uptake rate as compared to untreated glycerol source 1 because soap removal from crude glycerol promoted algal growth. Source 2 of crude glycerol, which is without methanol and soap resulted in 1.5 times the lipid productivity and substrate utilization rate when compared to untreated source 1 of crude glycerol, which had both soap and methanol.

From the above studies, it was found that purified glycerol gives better performance than crude glycerol and comparable performance when compared to pure glycerol. Hence, it is important to purify crude glycerol for obtaining a high lipid yield and concentration. 


\section{Removal of impurities in the crude glycerol}

Crude glycerol has different compositions depending on the feedstock and trans-esterification process. Hence, the purification process for crude glycerol largely depends on the usage of glycerol after purification and the effects of the impurities on the process, which would be part of cost control and profit measures. When the purified glycerol is used as a carbon source for fermentation medium, the presence of some contaminants is acceptable, which depends on the tolerance capacity of the strain. However, application of glycerol in food and pharmaceutical sectors, requires high glycerol purity. As a rule of thumb, a general purification of glycerol processes composed of three steps (Ardi et al., 2015). The first step involves the removal of soap and metals, which can be attained through precipitation during acidification, where soaps are converted to FFAs and metals precipitate in the form of salts. If alkaline (base) catalyst is used during the trans-esterification, acidic treatment is applied. If the acid catalyst is used during trans-esterification, base treatmenteatalyst is applied. The next step is to concentrate the glycerol through evaporation where alcohol is removed from the glycerol stream. The final step is the refining step, which can be achieved to the desired degree with a combination of methods like ion exchange, vacuum distillation, membrane technology and adsorption.

\subsection{Chemical treatment}

Acidification is the most common method as pre-treatment of glycerol purification processes, which involves a chemical reaction using a strong acid to remove catalyst $(\mathrm{NaOH}, \mathrm{KOH})$ and soaps. The reaction of an acid with soap will produce FFAs and reaction of acid with base catalyst would give salt and water. The insoluble free fatty acids will form a separate phase at the top and can be removed while precipitated salts can be removed through filtration. The acidification process usually separates the crude glycerol into three layers: fatty acids at the top, glycerol rich layer in the middle and inorganic salts at the bottom.

Crude glycerol was purified by acidification ( $\mathrm{pH}$ 1) using different acids, and the results were compared ( Nanda et al., 2014). Phosphoric acid gave the best results when compared to sulphuric and hydrochloric acid as phosphate salts are poorly soluble in the glycerol phase. Crude glycerol obtained from the biodiesel industry $(12 \% \mathrm{w} / \mathrm{w}$ glycerol, $70.2 \% \mathrm{w} / \mathrm{w}$ soap, $9.2 \% \mathrm{w} / \mathrm{w}$ water, $5.6 \% \mathrm{w} / \mathrm{w}$ ash) was acidified at $\mathrm{pH} 1$ using phosphoric acid for a total precipitation time of $1 \mathrm{~h}$, producing a purified product containing $96 \%(\mathrm{w} / \mathrm{w})$ glycerol, $1.3 \%$ $(\mathrm{w} / \mathrm{w})$ water, $1.04 \%(\mathrm{w} / \mathrm{w})$ ash, 1.09\% (w/w) soap. Acidification ( $\mathrm{pH}$ 1, phosphoric acid) reduced the $\mathrm{Na}$ concentration from $45.76 \mathrm{~g} / \mathrm{L}$ to $1.16 \mathrm{~g} / \mathrm{L}$ and $\mathrm{K}$ concentration from $0.14 \mathrm{~g} / \mathrm{L}$ to $0.082 \mathrm{~g} / \mathrm{L}$ in the purified glycerol. The density, viscosity, $\mathrm{pH}$ and metal contents of the purified glycerol products were analyzed and found to be very close to that of the commercially available pure glycerol.

The reduction of potassium and sodium during purification works by Eqs. (1) and (2):

$\mathrm{RCOOK}+\mathrm{H}_{3} \mathrm{PO}_{4} \rightarrow \mathrm{RCOOH}+\mathrm{KH}_{2} \mathrm{PO}_{4}$ (precipitate)

$\mathrm{RCOONa}+\mathrm{H}_{3} \mathrm{PO}_{4} \rightarrow \mathrm{RCCOH}+\mathrm{NaH}_{2} \mathrm{PO}_{4}$ (precipitate) 
We also investigated purification of crude glycerol (with high potassium concentration) using phosphoric acid by adjusting $\mathrm{pH}$ to 2 followed by overnight settling of the precipitate (unpublished data). It was found that the potassium concentration decreased from $73.04 \mathrm{~g} / \mathrm{L}$ in the crude glycerol to $7.6 \mathrm{~g} / \mathrm{L}$ in purified glycerol. However, phosphorus concentration increased from $0.18 \mathrm{~g} / \mathrm{L}$ in the crude glycerol to $23.7 \mathrm{~g} / \mathrm{L}$ in the purified glycerol due to the addition of phosphoric acid while glycerol concentration increased from $450 \mathrm{~g} / \mathrm{L}$ in the crude glycerol to $473 \mathrm{~g} / \mathrm{L}$ in purified glycerol.

Kongjao et al. (2010) reported that acidification of crude glycerol (glycerol purity 28\%) with $\mathrm{H}_{2} \mathrm{SO}_{4}$ to the desired $\mathrm{pH}$ of 1-6 increased the yield of glycerol-rich layer (Kongjao et al., 2010). High purity of glycerol (93.34\%) was obtained at $\mathrm{pH} 1$ followed by a series of chemical neutralization with $12.5 \mathrm{M} \mathrm{NaOH}$. Crude glycerol had the following composition (w/w): 28.56\% glycerol, 56.13\% soap, $6.7 \%$ water and 2.65\% ash. The purified glycerol obtained had $93.34 \%(\mathrm{w} / \mathrm{w})$ glycerol, $5.15 \%(\mathrm{w} / \mathrm{w})$ soap and $1.5 \%(\mathrm{w} / \mathrm{w})$ water. The soap could not be completely removed from the crude glycerol due to the reaction between excess $\mathrm{NaOH}$ and the dissolved short (C6-8) and medium chain (C10-14) fatty acids, generated from the soap hydrolysis in the acidic stages and then dissolved in the polar glycerol phase or the reaction with some of the short and medium chain methyl esters dissolved in the glycerol phase.

One study proposed the treatment of glycerol by the treatment with sulphuric acid at $\mathrm{pH} 3-4$, which converted soap present in the crude glycerol to higher fatty acids (Hájek and Skopal, 2010). Precipitated salts were removed by filtration through a frit type S1 (pore size $110 \mu \mathrm{m}$ ) and the excess of methanol was distilled off at $60{ }^{\circ} \mathrm{C}$, a pressure of $3 \mathrm{kPa}$ over a $50 \mathrm{~min}$ period. Crude glycerol had following composition (w/w): $53.1 \%$ glycerol, $21.8 \%$ soap, $11.7 \%$ water, $9.3 \%$ esters and $4.6 \%$ methanol while purified glycerol obtained after $\mathrm{pH}$ adjustment, filtration and distillation had $88.1 \%(\mathrm{w} / \mathrm{w})$ glycerol and $10.8 \%(\mathrm{w} / \mathrm{w})$ water.

Javani et al. (2012) proposed acidification of crude glycerol by phosphoric acid and production of potassium phosphate as by-product using repeated acidification (Javani et al., 2012). In the study, acidification of crude glycerol with phosphoric acid to 4.67 (precipitation of $\mathrm{KH}_{2} \mathrm{PO}_{4}$ ) was conducted to produce high quality potassium phosphate during glycerol purification. Washing of the filtered $\mathrm{KH}_{2} \mathrm{PO}_{4}$ with IPA (Iso-propyl alcohol) and heating to $90^{\circ} \mathrm{C}$ for 60 min recovered glycerol, free fatty acids (FFAs), $\mathrm{KH}_{2} \mathrm{PO}_{4}$ and $\mathrm{K}_{2} \mathrm{HPO}_{4}$, with a purity of $96.08 \%, 99.58 \%, 98 \%$ and $98.05 \%$, were obtained, respectively. The crude glycerol had following (w/w) composition (w/w): $40.6 \%$ glycerol, $41.03 \%$ soap, 14\% water and $4.37 \%$ ash while purified glycerol obtained after acidification had $96.08 \%$ glycerol $(\mathrm{w} / \mathrm{w})$ and $3.77 \%(\mathrm{w} / \mathrm{w})$ ash. The results showed that $\mathrm{K}_{2} \mathrm{HPO}_{4}$ produced was of commercial quality and could be implemented as a food additive in the food industry, buffering agent and fungicide. This is part of the strategy to economize biodiesel production while producing high quality FFAs, potassium phosphate and glycerol due to the high price of the products.

Chen et al. (2018b) purified crude glycerol using phosphoric acid. The purified glycerol was obtained by removing soap from crude glycerol with the addition of $\mathrm{H}_{3} \mathrm{PO}_{4}$. Phosphoric acid converted the soap to free fatty acids and then was allowed for phase separation after $72 \mathrm{~h}$. It was found that $2 \mathrm{~mL}$ phosphoric acid/ $40 \mathrm{~mL}$ crude glycerol solution resulted in $99.2 \%$ of FFA recovery. Crude glycerol had following composition (w/w): $31.8 \%$ glycerol, $21.1 \%$ soap, $24.4 \%$ water, $2.3 \%$ ash, $15.3 \%$ methanol and $2.8 \%$ catalyst while purified 
glycerol had 55\% (w/w) glycerol, 20.8\% (w/w) water, 4.2\% (w/w) ash and 18.5\% (w/w) methanol. Acidification using phosphoric acid completely removed soap and catalyst from the crude glycerol.

Acidification of crude glycerol results in conversion of soap to FFA, which can be either removed as the product or it can be utilized by the microbe for lipid production depending on its metabolism and tolerance. Acidification has also resulted in precipitation of phosphate or sulphate salts which have applications in food industry and as a buffering agent.

\subsection{Thermal treatment}

The second step in the general purification process is the removal of methanol. In the trans-esterification process, excess methanol is used during the trans-esterification to get high FAME yield. The excess methanol is distributed between the methyl ester and crude glycerol phase (Ardi et al., 2015). There is a serious concern for health, safety and environment as residual methanol present in both biodiesel and glycerol phase is toxic in nature. The emission of excess methanol can have serious effects on the environment and public health.

It is a common practice in the industry to remove alcohol from both glycerol and biodiesel streams through either an evaporator or a flash unit (Alves et al., 2013). The residual methanol in crude glycerol is evaporated during sterilization of crude glycerol. High methanol $(>20 \% \mathrm{w} / \mathrm{w})$ in the crude glycerol can be easily removed by vacuum distillation. Distillation is generally not applicable for streams which are sensitive to thermal degradation or polymerization at higher temperatures (Ardi et al., 2015). At temperatures higher than $200{ }^{\circ} \mathrm{C}$, polymerization of glycerol into polyglycerol occurs. Dehydration of glycerol occurs in slightly acidic conditions at temperature above $160^{\circ} \mathrm{C}$, and glycerol is oxidized to glycerose, glyceraldehyde and di-hydroxyl acetone. In order to prevent decomposition of glycerol, purification has to be done in a vacuum where the $\mathrm{pH}$, temperature and pressure are controlled. Hence, vacuum distillation is the most common method for glycerol purification (Alves et al., 2013; Xiao et al., 2013). For methanol removal, crude glycerol is treated under vacuum conditions using a rotary evaporator at $50-90{ }^{\circ} \mathrm{C}$ for $>2 \mathrm{~h}$ (Xiao et al., 2013).

In one of the studies, distilled glycerol was recovered from the crude glycerol residue by a simple vacuum distillation at $120^{\circ} \mathrm{C}-126^{\circ} \mathrm{C}$ and $0.4-0.04$ mbar pressure (Yong et al., 2001). The $\mathrm{pH}$ for the distillation was kept $<5$ in order to avoid foaming. Crude glycerol had following composition (w/w): 50.4\% glycerol, 8.6\% water, $17 \%$ ash and $24 \%$ matter organic non-glycerol (MONG). The components of MONG in the crude glycerol were glycerides, FFAs, oxidation products and the polymerized compounds of glycerol. Purified glycerol, contained after vacuum distillation had $96.6 \%(\mathrm{w} / \mathrm{w})$ glycerol, $1 \%(\mathrm{w} / \mathrm{w})$ water and $2.4 \%(\mathrm{w} / \mathrm{w})$ MONG. The components of MONG in the distilled glycerol were medium and short chain fatty acids and the oxidation products of glycerol, e.g. dihydroxyacetone, glyceraldehyde, hydroxy pyruvic aldehyde and tatronic dialdehyde.

The distillation process is a well-established technology and applicable for continuous operation at different scales. It requires low cost chemicals and it is highly adaptable for varying composition of crude glycerol ( Ardi et al., 2015). Thermal decomposition of glycerol is caused by the high-energy requirement for vaporization. Due to glycerol temperature susceptibility, use of falling film evaporators is suitable due to shorter contact time. Besides vacuum distillation, high methanol content $(>20 \% \mathrm{w} / \mathrm{w})$ in the crude glycerol can 
be completely removed from crude glycerol by 10 times dilution of crude glycerol sample with water and then passing through $0.2 \mu \mathrm{m}$ filter (Liang et al., 2010). Sterilization is sufficient for methanol removal from crude glycerol if the methanol concentration is less than $20 \%(\mathrm{w} / \mathrm{w})$ in the crude glycerol. For higher methanol concentration, vacuum distillation needs to be performed.

\subsection{Ion-exchange resins}

Ion-exchange resins are developed chemically and have shown their activity on glycerol purification due to the presence of functional groups present on their surface. Commercially, there are many different types of resins available, which are used at pilot scale (Faccini et al., 2011). Resins including Amberlite BD10 DRY®, Purolite PD 206®, Indion $®$ BF 170 and Lewatit ${ }^{\circledR}$ are already in use. The resin of the type AmberliteIRN-78 and Amberlite200 were used to purify crude glycerol and the resin performance was investigated (Isahak et al., 2010). For experiments, the ion-exchange resins were packed in a vertical column forming a bed. High Performance Liquid Chromatography (HPLC) was used to analyze the glycerol peak obtained from column elute.

Purification of glycerol by ion exclusion chromatography has also been evaluated on a laboratory scale using ion exclusion resin DOWEX 50 (Ardi et al., 2015). The crude glycerol with 7.5\% (w/w) glycerol was purified to $82.5 \%(\mathrm{w} / \mathrm{w})$ glycerol while salts in the crude glycerol were reduced from $13 \%(\mathrm{w} / \mathrm{w})$ to $7 \%(\mathrm{w} / \mathrm{w})$. By the method of recycling the elute (obtained from ion exchange chromatography), it is possible to obtain a glycerol concentration of near feed concentration while reducing the ionic content to a low value.

Carmona et al. (2009) reported that the macro-porous Amberlite could be used for sodium ion removal from glycerol/water solutions containing high salt concentrations at $45^{\circ} \mathrm{C}$. It was found that maximum ionexchange capacity is independent of the water content and the resin was capable of yielding technical grade glycerol from many different processes. Purification using Amberlit-252 was highly efficient because of its high regeneration cycles (5 times) without loss in its ion exchange capacity. Amberlite IR-120 and Amberlite IRA-420 were able to remove potassium and chloride ions from glycerol/ water solutions, respectively. Important parameters governing ion-exclusion chromatography include temperature, feed volume, solute concentration and resin matrix.

The application of ion exclusion to large scale purification is because of the low cost, operation simplicity and ease of scale-up. However, for glycerol purification using ion-exchange to be viable, there are several concerning issues that need to be resolved. These issues are fouling of resin by soaps and fatty acids, large quantities of wastewater produced and problems in the regeneration of the resin (Ardi et al., 2015).

\subsection{Adsorption using activated carbon (AC)}

Adsorption with activated carbon is mainly used as the finishing step to further refine the purified glycerol; reduce the color, in addition reducing some fatty acids and other components. Manosak et al. (2011) used a commercial activated carbon for color removal from crude glycerol. It was found that increasing the dose of activated carbon increased the color removal from the refined crude glycerol (Manosak et al., 2011). It was found that at $200 \mathrm{~g} \mathrm{AC/L}$ glycerol, a clear color (99.7\%) reduction was obtained. During this process, fatty 
acids like lauric acid and myristic acid were eliminated. The purified glycerol characteristics were according to the acceptable range of values of the BS 2621:1979.

A set of 15 activated carbon derived from sewage sludge was employed for removal of MONG and ash from the crude glycerol (Hunsom and Autthanit, 2013). Sludge derived activated carbon was prepared and activated using different chemicals, $\mathrm{KOH}, \mathrm{K}_{2} \mathrm{CO}_{3}$, and $\mathrm{H}_{3} \mathrm{PO}_{4}$. Crude glycerol was pre-treated using acidification by $\mathrm{H}_{3} \mathrm{PO}_{4}$ ( $\mathrm{pH} 2.5$ ) and purified using treatment with ACs. It was found that among all activated carbons, $\mathrm{KOH}-$ 800AC displayed the highest efficiency to adsorb impurities (MONG and ash) from pre-treated crude glycerol. Based on adsorption results, $\mathrm{KOH}-800 \mathrm{AC}$ improved glycerol purity as compared to the commercial activated carbon. The crude glycerol had following (w/w) composition: $27.2 \%$ glycerol, $36.2 \%$ ash and 36.6\% MONG while purified glycerol had $93 \%(\mathrm{w} / \mathrm{w})$ glycerol and $7 \%(\mathrm{w} / \mathrm{w})$ ash.

The surface chemistry and the textural properties of ACs play an important role in the adsorption of impurities from crude glycerol. The adsorption time and the agitation rate are the important parameters for the adsorptive purification of CG.

\subsection{Membrane technology}

Membrane technology is an emerging technology, which is cost-effective and provides decent performance when compared to the other glycerol purification processes. Although conventional methods, such as combinations of chemical and physical treatments (vacuum distillation, evaporation) produce good quality of

purified glycerol, they have disadvantages such as maintenance of the facilities, equipment and high operational costs pose major hurdles for optimization and cost control. The cost limitations are easily minimized and reduced with the implementation of membrane technology as it requires less energy. Several studies have been reported for glycerol purification based on membrane technology.

\subsubsection{Removal of palm oil and oleic acid from CG}

The effects of $\mathrm{pH}$, different palm oil concentrations, different oleic acid concentrations in crude glycerol solution on the membrane flux decline and rejection coefficient were examined using PVDF (polyvinylidene fluoride) $30 \mathrm{kDa}$ membrane (Mah et al., 2012). During ultrafiltration of $0.001-0.1 \mathrm{~g} / \mathrm{L}$ palm oil, the palm oil molecule tended to form big droplets, influencing the membrane performance. Within the range of $0.003-$ $0.1 \mathrm{~g} / \mathrm{L}$, the oleic acid molecule tended to form small droplets, which would clog into the membrane inter-pore. If a blend of palm oil and oleic acid was investigated, the percentage of flux decline would reduce significantly as compared to the palm oil or oleic acid alone. The acidic solutions had the higher flux decline percentage, which may be due to the high amount of undissociated oleic acid enhancing the pore restriction and blocking. The reason of lower flux decline percentage in neutral or alkaline solution may be due to conversion of acid into corresponding salts and the solubility of the salt in CG was higher than that of the acid. Lastly, PVDF $30 \mathrm{kDa}$ membrane is proven to be capable of removing palm oil and oleic acid from the glycerin solution with sustainable flux.

\subsubsection{Removal of tri-glycerides from crude glycerol}


Indok Nurul Hasyimah et al. (2011) reported two ultrafiltration (UF) polymeric membranes for clarification of glycerin-rich solutions containing triglycerides (TGs). The membranes were made of poly (ether sulfone) (PES) and poly-(vinylidene fluoride) (PVDF) having molecular-weight cut-off (MWCO) values of $25 \mathrm{kDa}$ and $30 \mathrm{kDa}$, respectively. It was found that hydrophilic membranes (PVDF) present a lower kinetic constant, which indicates that such membranes resist fouling and maintain high fluxes in the presence of oil. PVDF membranes were found to provide higher fluxes and lower TG rejection rates (81\%) than PES membranes (91\%). PES (hydrophobic membrane) are prone to the pore blocking and cake formation due to presence of tri-glycerides in feed, which are oleophilic in nature.

Membrane technology is considered a good alternative when compared to current methods for the glycerol purification process. The broad range of membranes applications and advantages are attracting researchers to develop crude glycerol purification methods using membrane technology. Despite the obvious advantages of low energy and cost, membrane technology has not yet been used in the industrial practice for glycerol purification. It is mainly due to the reasons such as membrane fouling, the durability of membranes and the availability of suitable membranes for specific operations.

\subsection{Calcium precipitation}

The saponified fatty acids (SFA) were removed from the crude glycerol by adding $25 \mathrm{~mL}$ of crude glycerol to $25 \mathrm{~mL}$ of appropriate molarity (between 0 and 1) of $\mathrm{CaCl}_{2}$ or $\mathrm{Ca}\left(\mathrm{NO}_{3}\right)_{2}$ (Pott et al., 2014). It was found that calcium soap precipitated out of the solution. As calcium is divalent, 2 mol of SFAs were removed for each mole of calcium added. The solid precipitate can be removed from the glycerol rich phase by centrifugation or filtration.

\subsection{Solvent extraction}

In another study, SFAs were removed from the crude glycerol by solvent extraction (Pott et al., 2014). Equal volumes of $50 \mathrm{vol} \%$ crude glycerol, hexane and various volumes of $12 \mathrm{M} \mathrm{HCl}(0-1.2 \mathrm{~mL})$ were added to a continuously agitated tube for $2 \mathrm{~h}$. It was found that the solvent extraction (to remove saponified fatty acids) was effective only when used in conjunction with $\mathrm{pH}$ adjustment. This is because salts of fatty acids are poorly soluble in non-polar solvents unless they become protonated by the addition of an acid. Solvent extraction with pH 7.6 was effective in removal of saponified fatty acids from crude glycerol.

\subsection{Combination of several techniques}

A universal procedure for crude glycerol purification has been developed for removal of soap, FFAs, FAMEs and glycerides (Xiao et al., 2013). The key steps for purification are initial microfiltration of the crude glycerol to remove solids, saponification and acidification of CG followed by phase separation to remove glycerides and free fatty acids and final biphasic extraction to obtain high purity of glycerol. The procedure was utilized to purify crude glycerol samples from two different sources. One CG sample with following composition (w/w): $74.5 \%$ glycerol, $19.8 \%$ soap, $4.6 \%$ FAMEs was purified to $95.6 \%(w / w)$ glycerol. Other CG sample with the following $(\mathrm{w} / \mathrm{w})$ composition: $53.2 \%$ glycerol, 32.4\% soap, 4.9\% FAMEs, $4.3 \%$ glycerides and $3.6 \%$ FFAs to $94.4 \%(\mathrm{w} / \mathrm{w})$ glycerol and $1.8 \%(\mathrm{w} / \mathrm{w})$ FAMEs. The combination of several techniques (filtration, 
saponification, acidification and solvent extraction) was able to remove soap, FAME, FFA and glycerides from crude glycerol (Xiao et al., 2013).

\subsection{Cost estimate of glycerol purification processes}

In one of the studies, the cost for glycerol purification using a combination of neutralization, centrifugation, evaporation and column distillation was estimated to be 0.149 USD $/ \mathrm{kg}$ crude glycerol (Wan Isahak et al., 2015 ). In another study, glycerol purification cost using physical adsorption process was $5.72 \mathrm{USD} / \mathrm{L}$ crude glycerol while glycerol purification using a combined process of chemical extraction using $n-\mathrm{C}_{3} \mathrm{H}_{7} \mathrm{OH}$ and physical adsorption was costlier (17.1 USD/L crude glycerol) (Wan Isahak et al., 2015). The major cost associated factors at industrial scale for chemical treatment method are chemical purchase cost and utility cost (electricity used during agitation). For vacuum distillation, the major cost imparting factor is the utility cost (electricity and steam). For ion-exchange resins and membrane technology, the major cost associated factors are membrane/resin purchase and regeneration cost. For activated carbon and low-cost adsorbents, the major cost factor is activation (physical or chemical prior to use) cost and regeneration cost. Different glycerol purification methods reported in the literature in terms of advantages and disadvantages are compared in table 4.

Table 4

(i) The presentation of Tables and the formatting of text in the online proof do not match the final output, though the data is the same. To preview the actual presentation, view the Proof.

Advantages and disadvantages of different glycerol purification techniques.

\begin{tabular}{|c|c|c|}
\hline Techniques & Advantages & Disadvantages \\
\hline $\begin{array}{l}\text { pHEhemieat } \\
\text { Treatment }\end{array}$ & $\begin{array}{l}\text { 1. Used as a pre-treatment } \\
\text { (neutralization by } \\
\text { 2reatment) } \\
\text { 3. Removal of soaps } \\
\text { produces high quality by- } \\
\text { patty acids) }\end{array}$ & $\begin{array}{l}\text { 1. Repeated Acidification would } \\
\text { result in low glycerol yield } \\
\text { 2. Requires further purification } \\
\text { to produce commercial } \\
\text { glycerol }\end{array}$ \\
\hline $\begin{array}{l}\text { Vacuum } \\
\text { distillation }\end{array}$ & $\begin{array}{l}\text { 1. Established Method } \\
\text { 2. Produce high quality } \\
\text { glycerol }\end{array}$ & $\begin{array}{l}\text { 1. High } \\
\text { demandeompound } \\
\text { 2. Unfeasible for small and } \\
\text { mediums scale industry }\end{array}$ \\
\hline Activated & Colour reduction & 1. \\
\hline
\end{tabular}




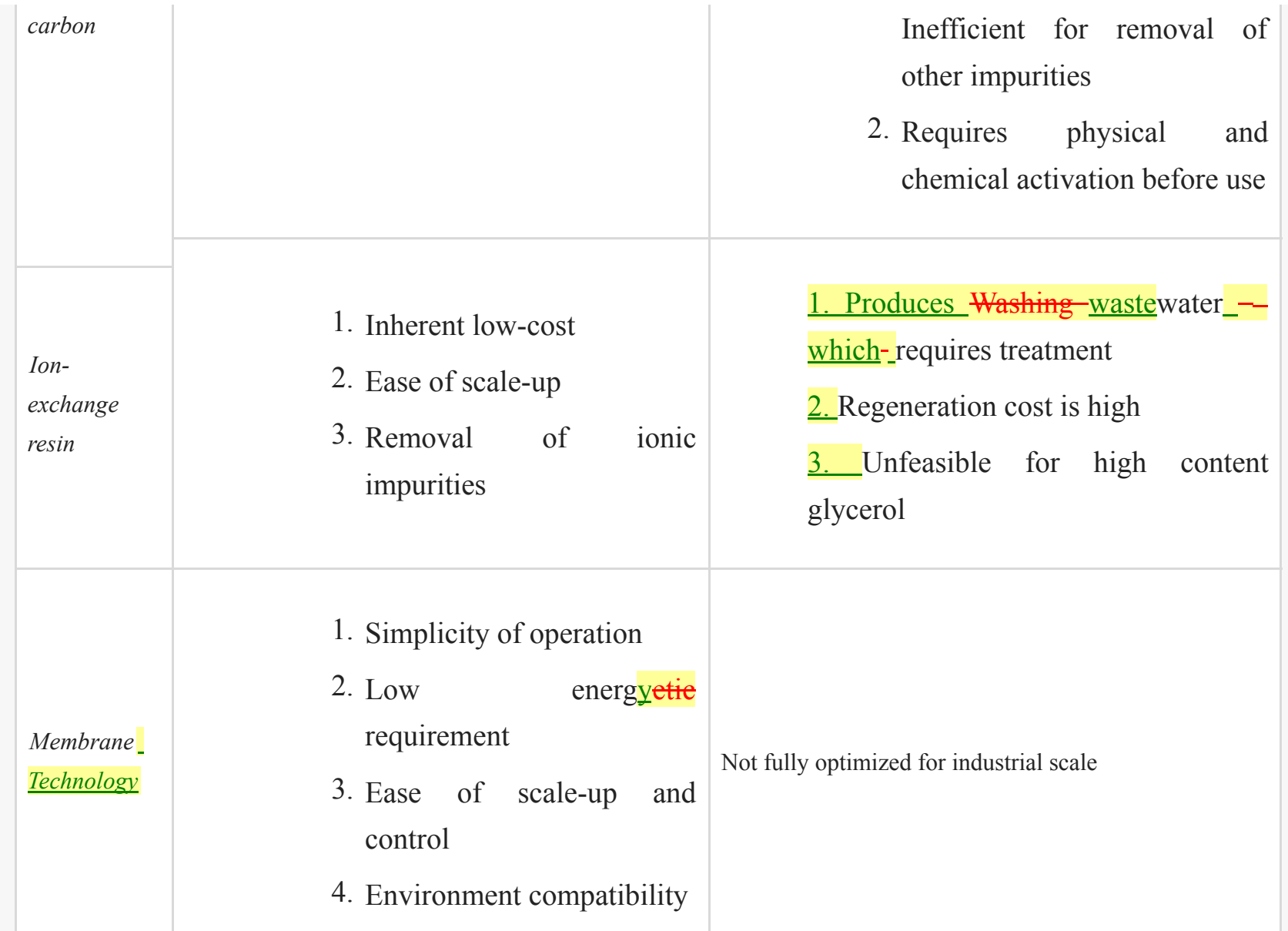

\subsection{Environmental sustainability of the purification techniques}

The major concern for use of membrane technology and ion-exchange resins in glycerol purification is the generation of wastewater during their regeneration. Toxic organic solvents are used during regeneration of membrane or resins which lead to wastewater generation. Use of activated carbon for glycerol purification requires physical activation (heating at $600-900^{\circ} \mathrm{C}$ ) prior to use. Activation requires large amounts of electricity and heating leading to GHG (greenhouse gas) emission during the process. Same is case for vacuum distillation or thermal treatment which requires electricity and steam leading to GHG emission. Also, methanol emission during vacuum distillation can have serious effects on the environment and public health. Acidification is the most effective technique as it generates purified glycerol, precipitated salts (of potassium or sodium) or free fatty acids which can be sold in the market. However, purified glycerol obtained after acidic treatment might require further treatment depending on its composition and the final usage.

\section{Challenges and future perspectives}

The impurities present in crude glycerol impact the metabolism of oleaginous microbes affecting the cell growth and lipid production. Hence, potential oleaginous microbes need to be screened, which can tolerate the impurities present in crude glycerol. Although studies have been reported for screening of microbes which has a high tolerance to impurities present in the crude glycerol (Kuttiraja et al., 2015; Kitcha and Cheirsilp, 2011), 
more microbes need to be screened and isolated that have a high tolerance for impurities present in crude glycerol.

Although acidic treatment was successful in removing potassium and sodium from crude glycerol in the form of precipitated salts, it may release phosphorus or sulphur ions into the purified glycerol solution due to the use of phosphoric or sulphuric acid, respectively. The phosphorus or sulphur ions in purified glycerol might affect the cellular metabolism of oleaginous microbes negatively depending on the strain and its metabolism. Moreover, purified glycerol obtained after acidic treatment needs neutralization by a base before being used as fermentation medium.

Vacuum distillation is effective for methanol removal from crude glycerol. However, thermal decomposition of glycerol is caused by high-energy input requirement for methanol vaporization. Glycerol purification needs to be conducted with falling film evaporators which have shorter contact time when compared to vacuum distillation.

Membrane technology has been reported for purification of crude glycerol. However, hydrophilic membranes can get fouled easily due to presence of soap and fatty acids in crude glycerol. Since hydrophilic membranes get fouled due to presence of soap in crude glycerol, membranes, which are resistant to soap should be looked upon to prevent fouling of the membrane. Moreover, pilot scale studies need to be conducted for purification of crude glycerol using membrane technology along with their techno-economic evaluation for feasibility of membrane technology at industrial scale.

Ion exchange resins are efficient for the removal of ionic impurities in crude glycerol. However, they are shipped with $\mathrm{H}^{+}$or $\mathrm{SO}_{3}{ }^{2-}$ ions which might get imparted in the glycerol during purification. Imparted $\mathrm{H}^{+}$or $\mathrm{SO}_{3}{ }^{2-}$ ions in glycerol can affect the cellular metabolism of oleaginous microbes negatively (depending on the strain). Some of the resins might get also fouled by fatty acids and soap in crude glycerol. Ion-exchange resins, which are resistant to soaps and fatty acids should be looked upon to prevent fouling of resins.

Low-cost adsorbents like sludge derived activated carbons (ACs) have been reported for purification of crude glycerol. However, studies on their recyclability are missing in the literature. To avoid frequent replacement of resins and adsorbents at large scale, regeneration studies should be conducted with low-cost solvents or varying temperature where desorption isotherms can be drawn to find out the best operating condition for regeneration. Although sludge derived activated carbons (ACs) have been reported for adsorptive purification of crude glycerol, more low-cost adsorbents need to be explored like agricultural/industrial wastes for glycerol purification along with their recyclability.

A solvent extraction technique has been reported for removal of saponified fatty acids from crude glycerol. However, it was effective when used in conjunction with $\mathrm{pH}$ adjustment. This is because salts of fatty acids are poorly soluble in non-polar solvents unless they become protonated by the addition of an acid. Moreover, solvents are expensive.

\section{Conclusion}


Crude glycerol composition is dependent on the feedstock and trans-esterification process. Contaminants in the crude glycerol may have a positive or negative effect depending on the strain, its metabolism and the concentration of the impurity. Although purified glycerol gives better performance than crude glycerol for lipid production, purified glycerol is expensive than crude glycerol. Hence, research should be directed for isolating oleaginous microbes, which can tolerate impurities in crude glycerol. Also, low-cost adsorbents should be looked upon for cost-effective glycerol purification and their recyclability should be evaluated.

\section{Acknowledgements}

Authors would like to acknowledge the Natural Sciences and Engineering Research Council of Canada (grant A4984, Canada Research Chair) for the financial support. The authors arewould also grateful to Miss Bhoomika Yadav (INRS-ETE) for her valuable suggestions for the manuscript.

\section{References}

(i) The corrections made in this section will be reviewed and approved by journal production editor.

Adewale, P., Dumont, M.J., Ngadi, M., 2015. Recent trends of biodiesel production from animal fat wastes and associated production techniques. Renew. Sustain. Energy Rev. 45, 574-588.

Alves, M.J., Nascimento, S.M., Pereira, I.G., Martins, M.I., Cardoso, V.L., Reis, M., 2013. Biodiesel purification using micro and ultrafiltration membranes. Renewable Energy 58, 15-20.

Anitha, M., Kamarudin, S.K., Kofli, N.T., 2016. The potential of glycerol as a value-added commodity. Chem. Eng. J. 295, 119-130.

Ardi, M., Aroua, M., Hashim, N.A., 2015. Progress, prospect and challenges in glycerol purification process: A review. Renew. Sustain. Energy Rev. 42, 1164-1173.

Ayoub, M., Abdullah, A.Z., 2012. Critical review on the current scenario and significance of crude glycerol resulting from biodiesel industry towards more sustainable renewable energy industry. Renew. Sustain. Energy Rev. 16 (5), 2671-2686.

Beopoulos, A., Chardot, T., Nicaud, J.-M., 2009. Yarrowia lipolytica: A model and a tool to understand the mechanisms implicated in lipid accumulation. Biochimie 91 (6), 692-696.

Carmona, M., Lech, A., de Lucas, A., Pérez, A., Rodriguez, J.F., 2009. Purification of glycerol/water solutions from biodiesel synthesis by ion exchange: sodium and chloride removal. Part II. J. Chem. Technol. Biotechnol. 84 (8), 1130-1135.

Chen, H., Zhang, Y., He, C., Wang, Q., 2014. Ca2+ signal transduction related to neutral lipid synthesis in an oil-producing green alga Chlorella sp. C2. Plant Cell Physiol. 55 (3), 634-644. 
Chen, J., Tyagi, R.D., Li, J., Zhang, X., Drogui, P., Sun, F., 2018. Economic assessment of biodiesel production from wastewater sludge. Bioresour. Technol. 253, 41-48.

Chen, J., Yan, S., Zhang, X., Tyagi, R.D., Surampalli, R.Y., Valéro, J., 2018. Chemical and biological conversion of crude glycerol derived from waste cooking oil to biodiesel. Waste Manage. 71, 164-175.

Chen, J., Zhang, X., Drogui, P., Tyagi, R.D., 2018. The pH-based fed-batch for lipid production from Trichosporon oleaginosus with crude glycerol. Bioresour. Technol. 259, 237-243.

Chen, J., Zhang, X., Tyagi, R.D., Drogui, P., 2018. Utilization of methanol in crude glycerol to assist lipid production in non-sterilized fermentation from Trichosporon oleaginosus. Bioresour. Technol. 253, 8-15.

Chen, J., Zhang, X., Yan, S., Tyagi, R.D., Drogui, P., 2017. Lipid production from fed-batch fermentation of crude glycerol directed by the kinetic study of batch fermentations. Fuel 209, 1-9.

Concas, A., Steriti, A., Pisu, M., Cao, G., 2014. Comprehensive modeling and investigation of the effect of iron on the growth rate and lipid accumulation of Chlorella vulgaris cultured in batch photobioreactors. Bioresour. Technol. 153, 340-350.

Dikshit, P.K., Moholkar, V.S., 2016. Kinetic analysis of dihydroxyacetone production from crude glycerol by immobilized cells of Gluconobacter oxydans MTCC 904. Bioresour. Technol. 216, 948957.

Dobrowolski, A., Mituła, P., Rymowicz, W., Mirończuk, A.M., 2016. Efficient conversion of crude glycerol from various industrial wastes into single cell oil by yeast Yarrowia lipolytica. Bioresour. Technol. 207, 237-243.

Faccini, C.S., Cunha, M.E.D., Moraes, M.S.A., Krause, L.C., Manique, M.C., Rodrigues, M.R.A., Benvenutti, E.V., Caramão, E.B., 2011. Dry washing in biodiesel purification: a comparative study of adsorbents. J. Braz. Chem. Soc. 22 (3), 558-563.

Ganesh, M., Senthamarai, A., Shanmughapriya, S., Natarajaseenivasan, K., 2015. Effective production of low crystallinity Poly (3-hydroxybutyrate) by recombinant E. coli strain JM109 using crude glycerol as sole carbon source. Bioresour. Technol. 192, 677-681.

Gao, Z., Ma, Y., Wang, Q., Zhang, M., Wang, J., Liu, Y., 2016. Effect of crude glycerol impurities on lipid preparation by Rhodosporidium toruloides yeast 32489. Bioresour. Technol. 218, 373-379.

Gong, Z., Shen, H., Zhou, W., Wang, Y., Yang, X., Zhao, Z.K., 2015. Efficient conversion of acetate into lipids by the oleaginous yeast Cryptococcus curvatus. Biotechnol. Biofuels 8 (1), 189.

Gong, Z., Zhou, W., Shen, H., Zhao, Z.K., Yang, Z., Yan, J., Zhao, M., 2016. Co-utilization of corn stover hydrolysates and biodiesel-derived glycerol by Cryptococcus curvatus for lipid production. Bioresour. Technol. 219, 552-558. 
Hájek, M., Skopal, F., 2010. Treatment of glycerol phase formed by biodiesel production. Bioresour. Technol. 101 (9), 3242-3245.

Huang, L., Xu, J., Li, T., Wang, L., Deng, T., Yu, X., 2014. Effects of additional Mg2+ on the growth, lipid production, and fatty acid composition of Monoraphidium sp. FXY-10 under different culture conditions. Ann. Microbiol. 64 (3), 1247-1256.

Hunsom, M., Autthanit, C., 2013. Adsorptive purification of crude glycerol by sewage sludge-derived activated carbon prepared by chemical activation with $\mathrm{H}_{3} \mathrm{PO}_{4}, \mathrm{~K}_{2} \mathrm{CO}_{3}$ and $\mathrm{KOH}$. Chem. Eng. J. 229 , $334-343$.

Indok Nurul Hasyimah, M., Mohammad, A.W., Markom, M., 2011. Influence of triglycerides on fouling of glycerol-water with ultrafiltration membranes. Ind. Eng. Chem. Res. 50 (12), 7520-7526.

Isahak, W., Ismail, M., Yarmo, M.A., Jahim, J.M., Salimon, J., 2010. Purification of crude glycerol from transesterification RBD palm oil over homogeneous and heterogeneous catalysts for the biolubricant preparation. J. Appl. Sci. (Faisalabad) 10 (21), 2590-2595.

Iyyappan, J., Baskar, G., Bharathiraja, B., Saravanathamizhan, R., 2018. Malic acid production from biodiesel derived crude glycerol using morphologically controlled Aspergillus niger in batch fermentation. Bioresour. Technol. 269, 393-399.

Iyyappan, J., Bharathiraja, B., Baskar, G., Jayamuthunagai, J., Barathkumar, S., 2018. Malic acid production by chemically induced Aspergillus niger MTCC 281 mutant from crude glycerol. Bioresour. Technol. 251, 264-267.

Javani, A., Hasheminejad, M., Tahvildari, K., Tabatabaei, M., 2012. High quality potassium phosphate production through step-by-step glycerol purification: a strategy to economize biodiesel production. Bioresour. Technol. 104, 788-790.

Ji, L., Lei, F., Zhang, W., Song, X., Jiang, J., Wang, K., 2019. Enhancement of bioethanol production from Moso bamboo pretreated with biodiesel crude glycerol: Substrate digestibility, cellulase absorption and fermentability. Bioresour. Technol. 276, 300-309.

Kavanová, M., Lattanzi, F.A., Grimoldi, A.A., Schnyder, H., 2006. Phosphorus deficiency decreases cell division and elongation in grass leaves. Plant Physiol. 141 (2), 766-775.

Kitcha, S., Cheirsilp, B., 2011. Screening of oleaginous yeasts and optimization for lipid production using crude glycerol as a carbon source. Energy Procedia 9, 274-282.

Kongjao, S., Damronglerd, S., Hunsom, M., 2010. Purification of crude glycerol derived from waste used-oil methyl ester plant. Korean J. Chem. Eng. 27 (3), 944-949.

Kosmela, P., Kazimierski, P., Formela, K., Haponiuk, J., Piszczyk, Ł., 2017. Liquefaction of macroalgae Enteromorpha biomass for the preparation of biopolyols by using crude glycerol. J. Ind. Eng. Chem. 56, 399-406. 
Kumar, L.R., Kaur, R., Yellapu, S.K., Zhang, X., Tyagi, R.D., 2019. Chapter 27 - Biodiesel Production From Oleaginous Microorganisms With Wastes as Raw Materials. In: Pandey, A., Larroche, C., Dussap, C.-G., Gnansounou, E., Khanal, S.K., Ricke, S. (Eds.), Biofuels: Alternative Feedstocks and Conversion Processes for the Production of Liquid and Gaseous Biofuels (Second Edition). Academic, Press, pp. $661-690$.

Kumar, L.R., Yellapu, S.K., Zhang, X., Tyagi, R.D., 2019. Energy balance for biodiesel production processes using microbial oil and scum. Bioresour. Technol. 272, 379-388.

Kuttiraja, M., Dhouha, A., Tyagi, R.D., 2018. Harnessing the Effect of pH on Lipid Production in Batch Cultures of Yarrowia lipolytica SKY7. Appl. Biochem. Biotechnol. 184 (4), 1332-1346.

Kuttiraja, M., Krishna, S., Dhouha, A., Tyagi, R.D., 2015. A substrate-based approach for the selection of oil-bearing heterotrophs from nitrogen-deficient soil for lipid production. Appl. Biochem. Biotechnol. 175 (4), 1926-1937.

Leite, G.B., Paranjape, K., Abdelaziz, A.E., Hallenbeck, P.C., 2015. Utilization of biodiesel-derived glycerol or xylose for increased growth and lipid production by indigenous microalgae. Bioresour. Technol. 184, 123-130.

Li, C., Gao, S., Yang, X., Lin, C.S.K., 2018. Green and sustainable succinic acid production from crude glycerol by engineered Yarrowia lipolytica via agricultural residue based in situ fibrous bed bioreactor. Bioresour. Technol. 249, 612-619.

Liang, K., Zhang, Q., Gu, M., Cong, W., 2013. Effect of phosphorus on lipid accumulation in freshwater microalga Chlorella sp. J. Appl. Phycol. 25 (1), 311-318.

Liang, Y., Sarkany, N., Cui, Y., Blackburn, J.W., 2010. Batch stage study of lipid production from crude glycerol derived from yellow grease or animal fats through microalgal fermentation. Bioresour. Technol. 101 (17), 6745-6750.

Liu, Y., Koh, C.M.J., Ji, L., 2011. Bioconversion of crude glycerol to glycolipids in Ustilago maydis. Bioresour. Technol. 102 (4), 3927-3933.

Luo, X., Ge, X., Cui, S., Li, Y., 2016. Value-added processing of crude glycerol into chemicals and polymers. Bioresour. Technol. 215, 144-154.

Lv, J.-M., Cheng, L.-H., Xu, X.-H., Zhang, L., Chen, H.-L., 2010. Enhanced lipid production of Chlorella vulgaris by adjustment of cultivation conditions. Bioresour. Technol. 101 (17), 6797-6804.

Mah, S.-K., Leo, C., Wu, T.Y., Chai, S.-P., 2012. A feasibility investigation on ultrafiltration of palm oil and oleic acid removal from glycerin solutions: flux decline, fouling pattern, rejection and membrane characterizations. J. Membr. Sci. 389, 245-256.

Manosak, R., Limpattayanate, S., Hunsom, M., 2011. Sequential-refining of crude glycerol derived from waste used-oil methyl ester plant via a combined process of chemical and adsorption. Fuel Process. 
Technol. 92 (1), 92-99.

Mathiazhakan, K., Ayed, D., Tyagi, R.D., 2016. Kinetics of lipid production at lab scale fermenters by a new isolate of Yarrowia lipolytica SKY7. Bioresour. Technol. 221, 234-240.

Mootabadi, H., Salamatinia, B., Bhatia, S., Abdullah, A.Z., 2010. Ultrasonic-assisted biodiesel production process from palm oil using alkaline earth metal oxides as the heterogeneous catalysts. Fuel $89(8), 1818-1825$.

Mota, C.J., Pinto, B.P., de Lima, A.L., 2017. Glycerol Utilization. In: Glycerol. Springer, pp. 11-19.

Naganuma, T., Uzuka, Y., Tanaka, K., 1985. Physiological factors affecting total cell number and lipid content of the yeast, Lipomyces starkeyi. J. General Appl. Microbiol. 31 (1), 29-37.

Nanda, M., Yuan, Z., Qin, W., Poirier, M., Chunbao, X., 2014. Purification of crude glycerol using acidification: effects of acid types and product characterization. Austin J. Chem. Eng. 1 (1), 1-7.

Pott, R.W., Howe, C.J., Dennis, J.S., 2014. The purification of crude glycerol derived from biodiesel manufacture and its use as a substrate by Rhodopseudomonas palustris to produce hydrogen. Bioresour. Technol. 152, 464-470.

Rahman, M.S., Xu, C.C., Qin, W., 2017. Biotransformation of biodiesel-derived crude glycerol using newly isolated bacteria from environmental consortia. Process Biochem. 63, 177-184.

Ratledge, C., Wynn, J.P., 2002. The biochemistry and molecular biology of lipid accumulation in oleaginous microorganisms. Adv. Appl. Microbiol. 51, 1-52.

Ren, H.-Y., Liu, B.-F., Kong, F., Zhao, L., Xie, G.-J., Ren, N.-Q., 2014. Enhanced lipid accumulation of green microalga Scenedesmus sp. by metal ions and EDTA addition. Bioresour. Technol. 169, 763-767.

Rzechonek, D.A., Dobrowolski, A., Rymowicz, W., Mirończuk, A.M., 2019. Aseptic production of citric and isocitric acid from crude glycerol by genetically modified Yarrowia lipolytica. Bioresour. Technol. 271, 340-344.

Šajbidor, J., Koželouhov'a, D., Ĉert'ik,, M., 1992. Influence of some metal ions on the lipid content and arachidonic acid production by Mortierella sp. Folia Microbiologica 37 (6), 404-406.

Sanford, S.D., White, J.M., Shah, P.S., Wee, C., Valverde, M.A., Meier, G.R., 2009. Feedstock and biodiesel characteristics report. Renewable Energy Group Report.

Shuib, S., Wan Nawi, W.N.N., Taha, E.M., Omar, O., Abdul Kader, A.J., Kalil, M.S., Abdul Hamid, A., 2014. Strategic feeding of ammonium and metal ions for enhanced GLA-rich lipid accumulation in Cunninghamella bainieri 2A1. Sci. World J. 173574.

Ta, T.M.N., Cao-Hoang, L., Phan-Thi, H., Tran, H.D., Souffou, N., Gresti, J., Marechal, P.-A., Cavin, J.F., Waché, Y., 2010. New insights into the effect of medium-chain-length lactones on yeast membranes. 
Importance of the culture medium. Appl. Microbiol. Biotechnol. 87 (3), 1089-1099.

Takagi, M., Yoshida, T., 2006. Effect of salt concentration on intracellular accumulation of lipids and triacylglyceride in marine microalgae Dunaliella cells. J. Biosci. Bioeng. 101 (3), 223-226.

Thompson, J.C., He, B.B., 2006. Characterization of crude glycerol from biodiesel production from multiple feedstocks. Appl. Eng. Agric. 22 (2), 261-265.

Veljković, V.B., Banković-Ilić, I.B., Stamenković, O.S., 2015. Purification of crude biodiesel obtained by heterogeneously-catalyzed transesterification. Renew. Sustain. Energy Rev. 49, 500-516.

Vivek, N., Sindhu, R., Madhavan, A., Anju, A.J., Castro, E., Faraco, V., Pandey, A., Binod, P., 2017. Recent advances in the production of value added chemicals and lipids utilizing biodiesel industry generated crude glycerol as a substrate-metabolic aspects, challenges and possibilities: an overview. Bioresour. Technol. 239, 507-517.

Wan Isahak, W.N.R., Che Ramli, Z.A., Ismail, M., Mohd Jahim, J., Yarmo, M.A., 2015. Recovery and Purification of Crude Glycerol from Vegetable Oil Transesterification. Sep. Purif. Rev. 44 (3), 250-267.

Wischral, D., Zhang, J., Cheng, C., Lin, M., De Souza, L.M.G., Pessoa, F.L.P., Pereira, N., Jr, Yang, S.T., 2016. Production of 1, 3-propanediol by Clostridium beijerinckii DSM 791 from crude glycerol and corn steep liquor: process optimization and metabolic engineering. Bioresour. Technol. 212, 100-110.

Xiao, Y., Xiao, G., Varma, A., 2013. A universal procedure for crude glycerol purification from different feedstocks in biodiesel production: experimental and simulation study. Ind. Eng. Chem. Res. 52 (39), $14291-14296$.

Xin, F., Chen, T., Jiang, Y., Lu, J., Dong, W., Zhang, W., Ma, J., Zhang, M., Jiang, M., 2017. Enhanced biobutanol production with high yield from crude glycerol by acetone uncoupled Clostridium sp. strain CT7. Bioresour. Technol. 244, 575-581.

Xu, J., Zhao, X., Wang, W., Du, W., Liu, D., 2012. Microbial conversion of biodiesel byproduct glycerol to triacylglycerols by oleaginous yeast Rhodosporidium toruloides and the individual effect of some impurities on lipid production. Biochem. Eng. J. 65, 30-36.

Yang, X., Jin, G., Gong, Z., Shen, H., Bai, F., Zhao, Z.K., 2014. Recycling biodiesel-derived glycerol by the oleaginous yeast Rhodosporidium toruloides Y4 through the two-stage lipid production process. Biochem. Eng. J. 91, 86-91.

Yellapu, S.K., Bezawada, J., Kaur, R., Kuttiraja, M., Tyagi, R.D., 2016. Detergent assisted lipid extraction from wet yeast biomass for biodiesel: A response surface methodology approach. Bioresour. Technol. 218, 667-673.

Yellapu, S.K., Kaur, R., Kumar, L.R., Tiwari, B., Zhang, X., Tyagi, R.D., 2018. Recent developments of downstream processing for microbial lipids and conversion to biodiesel. Bioresour. Technol. 256, 515528. 
Yellapu, S.K., Kaur, R., Tyagi, R.D., 2017. Detergent assisted ultrasonication aided in situ transesterification for biodiesel production from oleaginous yeast wet biomass. Bioresour. Technol. 224, $365-372$.

Yellapu, S.K., Klai, N., Kaur, R., Tyagi, R.D., Surampalli, R.Y., 2019. Oleaginous yeast biomass flocculation using bioflocculant produced in wastewater sludge and transesterification using petroleum diesel as a co-solvent. Renewable Energy 131, 217-228.

Yenush, L. 2016. Potassium and Sodium Transport in Yeast.

Yong, K., Ooi, T., Dzulkefly, K., Wan Yunus, W., Hazimah, A., 2001. Refining of crude glycerine recovered from glycerol residue by simple vacuum distillation. J. Oil Palm Res. 13, 39-44.

Zhang, X., Chen, J., Wu, D., Li, J., Tyagi, R.D., Surampalli, R.Y., 2019. Economical lipid production from Trichosporon oleaginosus via dissolved oxygen adjustment and crude glycerol addition. Bioresour. Technol. 273, 288-296.

Zhang, X., Chen, J., Yan, S., Tyagi, R.D., Surampalli, R.Y., Li, J., 2017. Lipid production for biodiesel from sludge and crude glycerol. Water Environ. Res. 89 (5), 424-439.

Zhang, X., Yan, S., Tyagi, R.D., Surampalli, R.Y., Valéro, J.R., 2016. Energy balance of biofuel production from biological conversion of crude glycerol. J. Environ. Manage. 170, 169-176.

Zhou, C.-H.C., Beltramini, J.N., Fan, Y.-X., Lu, G.M., 2008. Chemoselective catalytic conversion of glycerol as a biorenewable source to valuable commodity chemicals. Chem. Soc. Rev. 37 (3), 527-549.

\section{Graphical abstract}

Figure Replacement Requested

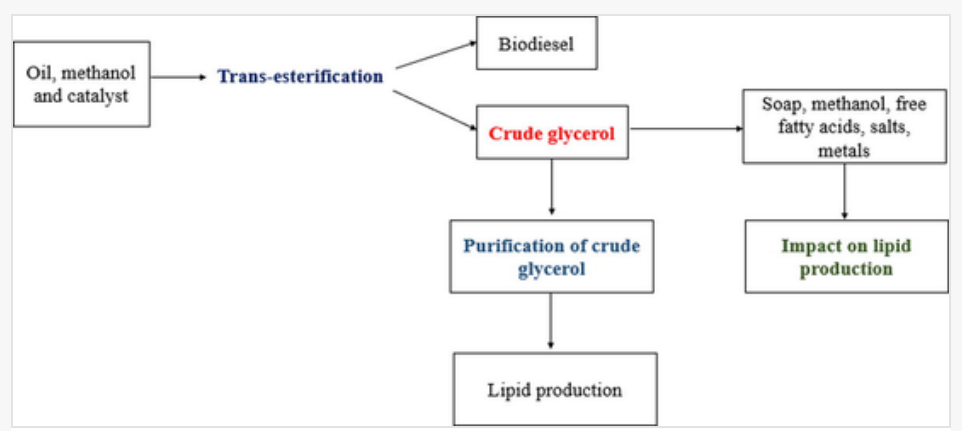




\section{Highlights}

- Crude glycerol composition is dependent on trans-esterification process.

- Impact of impurities on lipid production is dependent on their concentration and the strain tolerance.

- Purified glycerol gives better results than crude glycerol.

- Choice of glycerol purification technique is dependent on the final usage of glycerol.

\section{Queries and Answers}

Query: Your article is registered as belonging to the Special Issue/Collection entitled "WROC". If this is NOT correct and your article is a regular item or belongs to a different Special Issue please contact 1.daniel@elsevier.com immediately prior to returning your corrections.

Answer: Yes

Query: The author names have been tagged as given names and surnames (surnames are highlighted in teal color). Please confirm if they have been identified correctly.

Answer: Yes

Query: Have we correctly interpreted the following funding source(s) and country names you cited in your article: Natural Sciences and Engineering Research Council of Canada, Canada? /

Answer: Yes

Query: Correctly acknowledging the primary funders and grant IDs of your research is important to ensure compliance with funder policies. We could not find any acknowledgement of funding sources in your text. Is this correct? / Answer: Primary funder is Natural sciences and Engineerng Research Council of Canada and grant ID is A4984 
